\title{
Spiral-shaped reactor for water disinfection
}

\author{
Sofiane Soukane ${ }^{\mathrm{a}}$, Fariza Ait-Djoudia, Wahib M. Naceur ${ }^{\mathrm{a}}$, Noreddine Ghaffour ${ }^{\mathrm{b}}$ \\ ${ }^{a}$ Process Engineering Department, Faculty of Technology, University of Blida 1, Blida 09000, Algeria, \\ Email: ssoukane@gmail.com \\ ${ }^{b}$ King Abdullah University of Science and Technology (KAUST), Water Desalination and Reuse Center (WDRC), \\ Biological and Environmental Science and Technology Division (BESE), Thuwal 23955-6900, Saudi Arabia, Tel. \\ +966-218082180, Email: noreddine.ghaffour@ kaust.edu.sa
}

\begin{abstract}
Chlorine based processes are still widely used for water disinfection. The disinfection process for municipal water consumption is usually carried out in large tanks, specifically designed to verify several hydraulic and disinfection criteria. The hydrodynamic behavior of contact tanks of different shapes, each with an approximate total volume of $50,000 \mathrm{~m}^{3}$, was analyzed by solving turbulent momentum transport equations with a computational fluid dynamics (CFD) code, namely ANSYS fluent. Numerical experiments of a tracer pulse were performed for each design to generate flow through curves and investigate species residence time distribution for different inlet flow rates, ranging from $3 \mathrm{~m}^{3} \cdot \mathrm{s}^{-1}$ to $12 \mathrm{~m}^{3} \cdot \mathrm{s}^{-1}$. A new nature inspired Conch tank design of which shape follows an Archimedean spiral was then developed. The spiral design is shown to strongly outperform the other tanks designs for all the selected plug flow criteria with an enhancement in efficiency, less short-circuiting and an order of magnitude improvement in mixing and dispersion. Moreover, following the intensification philosophy, after $50 \%$ reduction of its size, the new design retains its properties and still gives far better results than the classical shapes.
\end{abstract}

Key words: Chlorination tanks; Water disinfection; CFD; Tank design; Disinfection criteria. 


\section{Introduction}

Water related to human activity has to be of proper quality to avoid waterborne diseases. Aquatic environment may undergo microbial contamination thus compromise secure water usage. For public health, it is necessary to reduce water microbial contamination. Water disinfection for public consumption has been used with great efficiency to destroy or inactivate pathogenic micro-organisms. Since the discovery of chlorine and its usage as a disinfectant [1, 2], the number of diseases related to water consumption has decreased considerably due to the destruction of microorganisms harmful to health [3]. Although other alternatives emerged such as ozonation and UV disinfection, chlorine remains widely used, as the process has proved its efficiency at low price and simple technology. It ensures a high demand for human consumption while complying with microbiological criteria and sustains the necessary residual chlorine to maintain water quality during distribution. However, chlorine also reacts with natural organic compounds, such as humic matter to produce carcinogenic species [4, 5] which unfortunately cannot be totally removed prior to disinfection even with the latest technologies. These chemical reactions produce more than 250 different disinfection by-products (DBP) [6], while other studies report more than 600 species in drinking water [7], among which are the trihalomethanes (THMs) such as chloroform, haloacetic acids (HAAs) such as chloroacetic acid or haloactonitrile (HANs) such as Cyanogen chloride. THMs and HAAs received much attention due to their relatively high concentration [8], although compounds with smaller concentrations might present a higher risk to human health [7]. DBPs concentration in drinkable water may depend on several factors, including the type of organic compounds, free chlorine concentration, $\mathrm{pH}$ value, temperature, and contact time and one has to act upon the enumerated factors to minimize their production. Therefore, tank design faces a multi-objective target since it has to remove microorganisms while avoiding excessive production of disinfection by-products.

Disinfection phenomena have often been considered as chemical reactions [9-12]. Consequently, species transport and subsequent residence time in a disinfection tank is of critical importance. A proper disinfection tank design has to ensure a suitable contact time in order to inactivate most of the microorganisms without the formation of by-products. Several investigations have been carried out to evaluate contact tank design and efficiency [13-18]. It has been shown that throughput of contact tanks can be improved by simple geometrical modifications, such as the 
insertion of baffles or guiding walls [19-21]. Unfortunately, such changes do not always bring the tank behavior enough close to plug flow. In-depth understanding of the flow is necessary, which requires advanced numerical tools and techniques. Indeed, hydrodynamic analysis (velocity distribution, location of recirculation loops) of large contact tanks aimed for drinkable water distribution cannot be obtained analytically. Moreover, on-site parameters are dynamic and one cannot afford lengthy experimental investigations. Hence, any modification brought to increase hydraulic efficiency can be undertaken with the help of CFD tools [14, 20, 22-25]. A thorough analysis aims to enable a uniform distribution of chlorine in the tank and the elimination of dead zones.

Firstly, three different tank geometries are compared [26]. Hydrodynamic behavior is investigated using a CFD tool and numerical experiments of a tracer pulse at the tank inlets are carried out. Outlet tracer responses are compared for each case to assess the ability of each design to respond to basic disinfection criteria. Secondly, a novel design was proposed of which performances are compared to the classical geometries.

\section{Contact tank design}

It is important to emphasize that contact tanks are not mixing chambers and chlorine has to be thoroughly mixed with water prior to enter the contact tank [27]. Depending on the diameter size of the pipes before the contact tank inlet, mixing can be carried out either by mechanical mixers or directly injected at the center of the flow. Once mixed, plug flow with high turbulence is desired [27]. The tank is therefore developed in such a way that the fluid moves in parallel streamlines with a uniform velocity [28]. Indeed, contact tanks are designed to behave as closely as possible to ideal reactors for the species residence time to be equivalent to the hydraulic contact time. In order to satisfy a desired disinfection degree, the latter has to comply with a preset product of the residual concentration of free chlorine $\mathrm{C}$ by the contact time $\mathrm{T}$ defined as the time at which $10 \%$ of the disinfectant is collected at the tank outlet [27]. This product is commonly called CT and is often used by practitioners. Its optimization is imperative since the contact between an oxidant and the water to treat leads to undesirable by-products of which concentration increases with CT. The latter can be adjusted using CFD analysis by attempting 
flow modifications based on tracer's numerical pulses at the tank entrance, to even out the real contact time instead of acting upon the active chlorine demand treatment rate $\mathrm{C}$.

Several factors can be used to assess tank efficiency. Practically, it is of interest to investigate the time needed for the first $10 \%$ of the tracer's total mass to leave the tank. The observed time, denoted $t_{10}$, divided by the hydraulic residence time (flow at the inlet/total volume) gives an insight into the gap between the actual residence time and the one corresponding to an ideal tank. The value of $t_{10}$ generally varies between 0.1 and 0.2 for most basic tank geometries, but can be enhanced to $0.5-0.7$ by adding baffles [29]. The effect of baffles on contact tank efficiency is still the subject of recent analyses $[18,30]$.

The starting design is based on the disinfection tank of Boudouaou's treatment plant located $30 \mathrm{~km}$ east of Algiers - Algeria. The plant has been built in 1987 to treat water from BéniAmrane (36 $\left.46^{\prime} 12.97^{\prime \prime} \mathrm{N}-3^{\circ} 36^{\prime} 27.67^{\prime \prime} \mathrm{E}\right)$ and Keddara $\left(36^{\circ} 39^{\prime} 9.19^{\prime \prime} \mathrm{N}-3^{\circ} 25^{\prime} 22.38^{\prime \prime E}\right)$ dams. It uses gaseous chlorine as disinfectant. The tank has a rectangular shape with a length of $128 \mathrm{~m}$ long, a width of $88 \mathrm{~m}$ and a height of $6 \mathrm{~m}$, as shown in Figure 1.

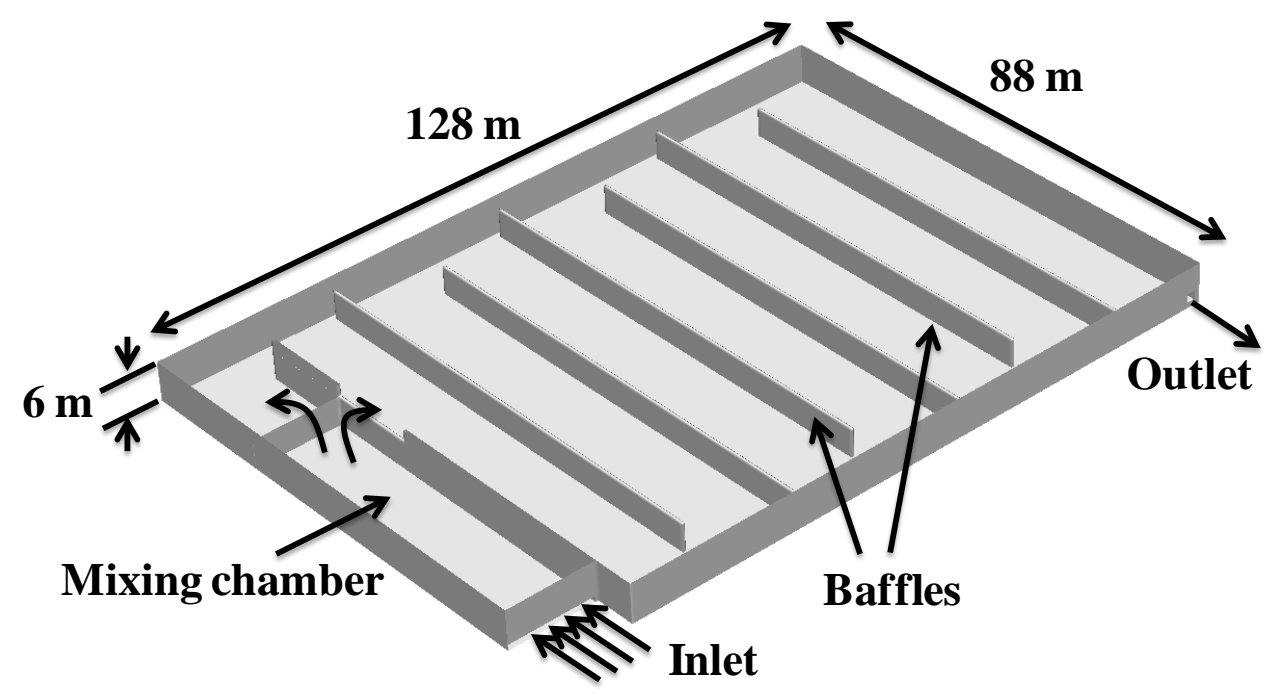

Figure 1. Disinfection tank of Boudouaou plant (East Algiers - Algeria). 


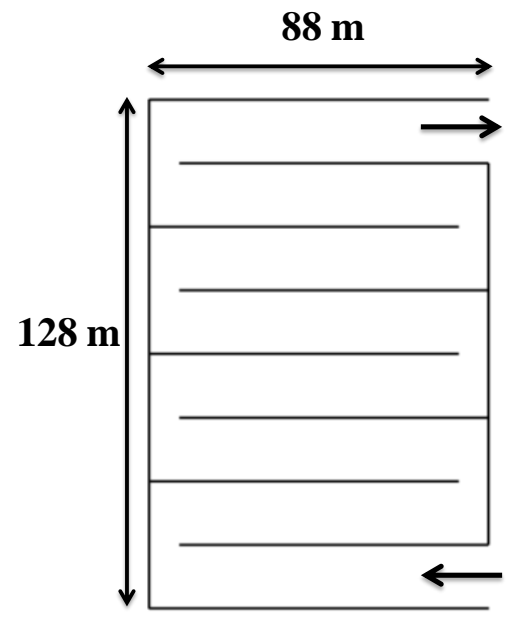

(a)

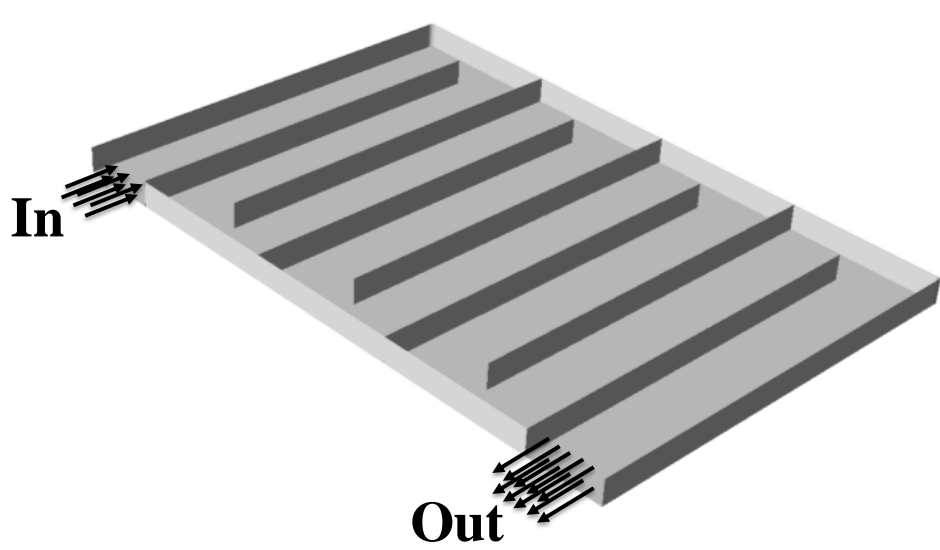

(b)

Figure 2. Rectangular design: (a) top view, (b) three dimensional view.

The utile volume is $50,000 \mathrm{~m}^{3}$, which corresponds to a water height of approximately $5 \mathrm{~m}$. The tank has six baffles constituting seven guided channels, which results in over $600 \mathrm{~m}$ of total flow length. Pretreated water enters the mixing chamber through a slit at the bottom (see Figure 1), then flows over the guided channels from two sides. Water finally exits through a relatively small opening at the opposite corner of the tank.

In order to eliminate any tank design artifact and analyze only channel shape effect, the contact chamber is blended with the tank channels resulting in a total tank volume of $56,320 \mathrm{~m}^{3}$. As depicted in Figure 2, inlet and outlet are simplified for the fluid to enter and leave the tank through the entire channel section.

The second design departs from the first one by smoothing out the right angles wherever the fluid reverses flow direction (see Figure 3). It has to be noted that there is no attempt to keep exactly the same total volume as long as the same order of magnitude is maintained. A design similar to the one presented by Fidaros et al. is reached [26] with a total volume of $47,000 \mathrm{~m}^{3}$ (see Figure 4). 


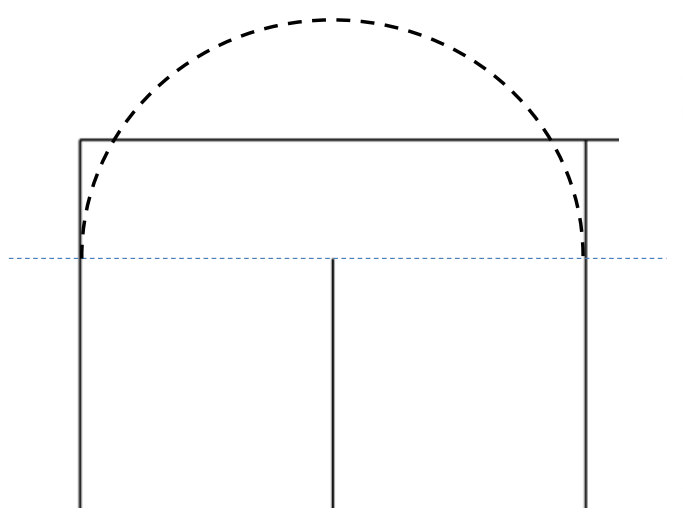

(a)

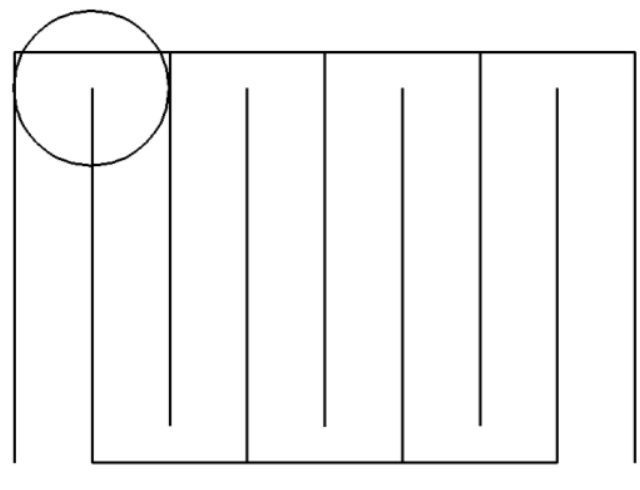

(b)

Figure 3. Corners smoothing of the rectangular design: (a) zoom over the tank corner, (b) top view.

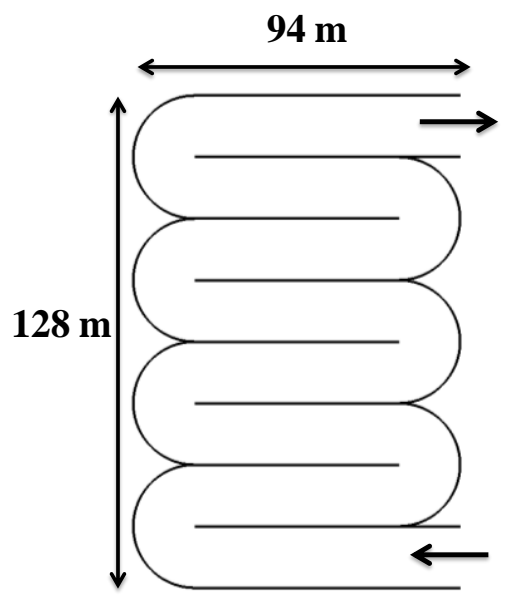

(a)

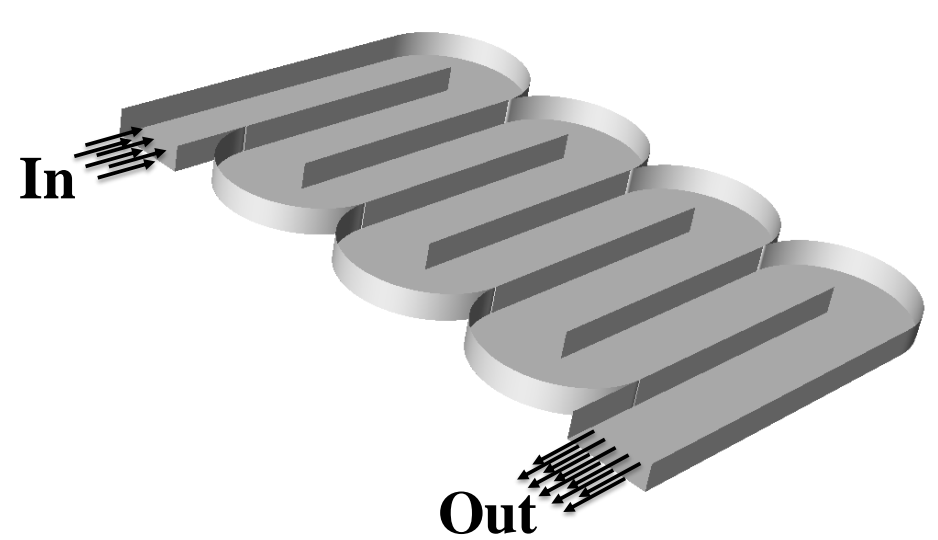

(b)

Figure 4. Semicircular design: (a) top view, (b) three dimensional view.

The third design, also presented by Fidaros et al. [26], as depicted in Figure 5 has a circular shape with a radius of $56 \mathrm{~m}$. The contact tank has two adjacent openings and circular inner walls in such a way that the inner channel width is kept constant, except at the center. The resulting total water volume that corresponds to a $5 \mathrm{~m}$ height is $49,260 \mathrm{~m}^{3}$. 


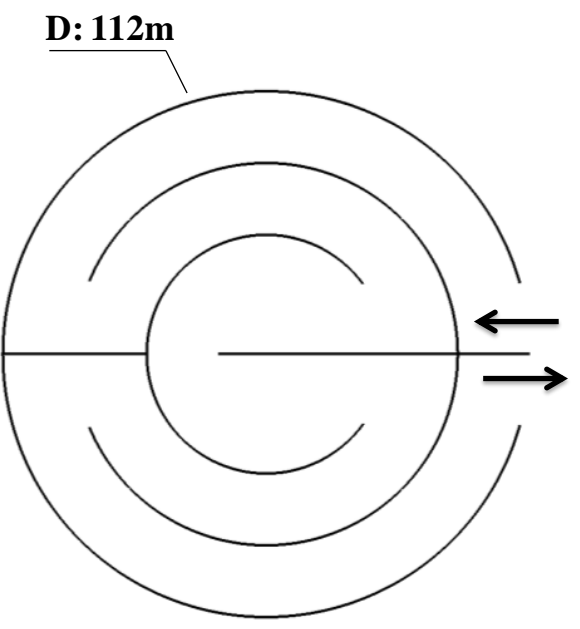

(a)

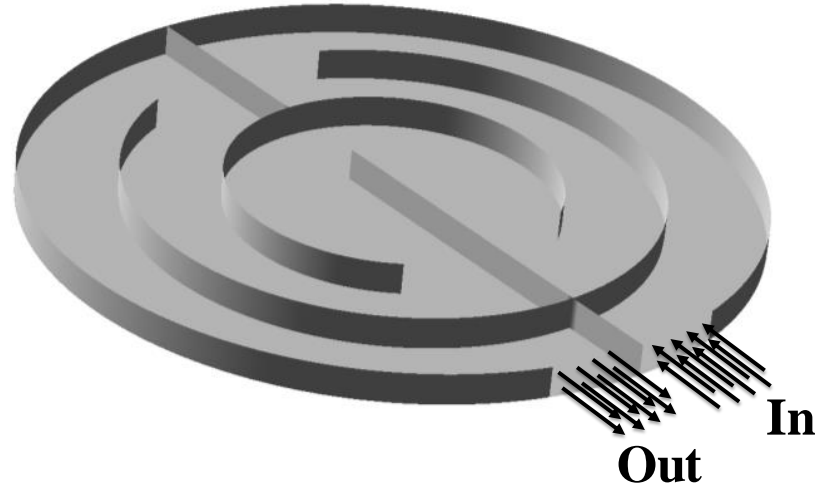

(b)

Figure 5. Circular design: (a) top view, (b) three dimensional view.

\section{CFD modeling}

Numerical modeling offers several advantages such as the investigation of a wide range of operating conditions, thus avoiding expensive experimental tests. Numerical models mainly focus on tracer transport in order to assess chlorine behavior in tanks. However, tracer behavior depends mainly on momentum, raising the need to couple transport equations. Early efforts provided two-dimensional analysis of momentum and tracer transport using finite differences method with appropriate discretization stencils [16, 31, 32]. With the use of commercial CFD tools and powerful mesh generation software, the analysis of contact tanks entered a new era with unlimited possibilities of tank design. Stamou [19, 22] used CFX [33] to analyze the effect of guiding walls on tank efficiency using calculated flow through curves (FTC) information. Starting from new or existing tank configurations, CFD simulations are carried out with geometrical improvements such as feature addition, until a satisfactory design is reached. In the present work, ANSYS Fluent 13 [34] is used for all numerical simulations. The flow is assumed fully turbulent for the whole range of flow rates considered. Although modeling residence time distribution (RTD) of effluents in disinfection contactors was shown to be very sensitive to the turbulence model [35], the default standard $k-\varepsilon$ turbulence model, extensively used in chlorine contact tanks modeling [36], is adopted. 


\subsection{Mesh generation}

Mesh generation for each tank design starts with a paving of the bottom surface followed by an extrusion to achieve the desired tank height. The concept is illustrated in Figure 6 for the circular design (please note that actual meshes are much finer and the one in Figure 6 is only given for visualization purposes).

\section{Extrusion direction}

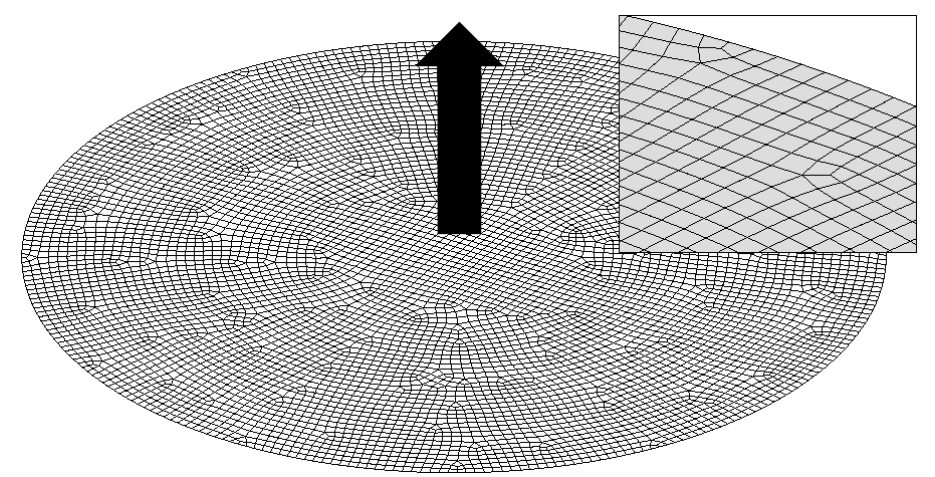

Figure 6. Example of bottom surface paving and extrusion direction for the circular design.

A series of calculations were carried out with increasing mesh sizes. For all tank designs, increasing the mesh from 140,000 elements to over 500,000 resulted in less than 15\% change in the RTD of a numerical tracer. In order to minimize the CPU time of transient tracer transport calculations, the mesh is kept to a minimum. Most importantly, particular care is taken to build meshes with similar density for all tanks under investigation in order to conduct a proper tank performance comparison. The total number of hexahedral elements used is approximately 142,000 for the circular design, 149,000 for the rectangular design, and 146,000 for the semicircular design.

\subsection{Governing equations and Boundary conditions}

The Reynolds averaged equations with the standard $k-\varepsilon$ turbulent model as implemented in ANSYS-fluent are considered [37]: 


$$
\begin{gathered}
\frac{\partial \rho}{\partial t}+\frac{\partial}{\partial x_{i}}\left(\rho u_{i}\right)=0 \\
\frac{\partial}{\partial}\left(\rho u_{i}\right)+\frac{\partial}{\partial}\left(\rho u_{i} u_{j}\right)=-\frac{\partial p}{\partial x_{i}}+\frac{\partial}{\partial x_{j}}\left\{\mu\left(\frac{\partial u_{i}}{\partial x_{j}}+\frac{\partial u_{j}}{\partial x_{i}}-\frac{2}{3} \delta_{i j} \frac{\partial u_{l}}{\partial x_{l}}\right)\right\}+\frac{\partial}{\partial x_{j}}\left(-\rho \overline{u_{i}^{\prime} u_{j}^{\prime}}\right)
\end{gathered}
$$

Using the Boussinesq approximation the Reynolds stress for isotropic turbulence is given by [22]:

$$
-\rho \overline{u_{i}^{\prime} u_{j}^{\prime}}=\mu_{t}\left(\frac{\partial U_{i}}{\partial x_{j}}+\frac{\partial U_{j}}{\partial x_{i}}\right)-\frac{2}{3} \rho k \delta_{i j}
$$

and the eddy viscosity by:

$$
\mu_{t}=\rho c_{\mu} \frac{k^{2}}{\varepsilon}
$$

where $c_{\mu}$ is a constant. The average turbulent kinetic energy $k$ and the turbulent kinetic energy dissipation rate $\varepsilon$ are given respectively by [22, 37]:

$$
\begin{gathered}
k=\frac{1}{2}\left(\overline{u_{1}^{2}}+\overline{u_{2}^{2}}+\overline{u_{3}^{2}}\right) \\
\varepsilon=\frac{\mu}{\rho}\left(\overline{\frac{\partial u_{i}}{\partial x_{j}} \frac{\partial u_{j}}{\partial x_{i}}}\right)
\end{gathered}
$$

The transport equations for the turbulent kinetic energy and the dissipation rate are given by:

$$
\begin{gathered}
\frac{\partial}{\partial}(\rho k)+\frac{\partial}{\partial x_{j}}\left(\rho k u_{i}\right)=\frac{\partial}{\partial x_{j}}\left\{\left(\mu+\frac{\mu_{t}}{\sigma_{k}}\right) \frac{\partial k}{\partial x_{j}}\right\}+G_{k}-\rho \varepsilon \\
\frac{\partial}{\partial}(\rho \varepsilon)+\frac{\partial}{\partial x_{j}}\left(\rho \varepsilon u_{i}\right)=\frac{\partial}{\partial x_{j}}\left\{\left(\mu+\frac{\mu_{t}}{\sigma_{\varepsilon}}\right) \frac{\partial \varepsilon}{\partial x_{j}}\right\}+C_{1 \varepsilon} \frac{\varepsilon}{k} G_{k}-C_{2 \varepsilon} \rho \frac{\varepsilon^{2}}{k}
\end{gathered}
$$

where $G_{k}$ represents the generation of turbulent kinetic energy due to mean velocity gradients, viz,

$$
G_{k}=\mu_{t} S^{2}
$$

and $S$ represents the magnitude of the mean rate of strain tensor expressed as: 


$$
S=\sqrt{2 S_{i j} S_{i j}}
$$

with,

$$
S_{i j}=\frac{1}{2}\left(\frac{\partial u_{j}}{\partial x_{j}}+\frac{\partial u_{i}}{\partial x_{j}}\right)
$$

Appropriate conditions are imposed at the domain boundaries. At the inlet, knowing the flow rate $Q$ and the inlet cross section $A_{i n}$, a normal velocity $u_{n}$ is imposed via:

$$
u_{n}=\frac{Q}{A_{\text {in }}}
$$

The turbulent energy and the dissipation rate are assumed uniform with values leading to an eddy viscosity equal to 90 times the viscosity of water [19]. The condition at the free surface is represented by a zero shear stress, assuming that the fluid surface is stable during the disinfection process [36, 38], viz.

$$
\tau_{s}=0
$$

where $\tau_{s}$ is the shear stress at the fluid free surface.

At solid boundaries (tank bottom surface, side walls and baffles), a no-slip boundary condition is assumed:

$$
u_{w}=0
$$

where $u_{w}$ denotes the fluid velocity at the walls.

\section{Numerical experiments}

Disinfection tanks are considered as large chemical reactors and will be analyzed as such [19, 20, 22, 39]. Therefore, they are often designed to behave as closely as possible to ideal reactors. Unfortunately, real tanks deviate from the ideal case and an evaluation of the deviation extent is desirable. This is classically handled in reactor design by analyzing three different interrelated factors, namely, the residence time distribution (RTD) or exit age distribution $\mathbf{E}$, the state of 
aggregation, and the earliness or lateness of mixing [40]. Focus is set on the exit age distribution $\mathbf{E}\left(\right.$ time $\left.^{-1}\right)$ which is often represented by a normalized distribution [40], viz.

$$
\int_{0}^{\infty} \mathbf{E} d t=1
$$

The $\mathbf{E}$ curve is also called normalized average FTC and is therefore plotted to analyze the reactor behavior.

There are two different experimental procedures to find the $\mathbf{E}$ curve, namely; the pulse experiment and the step experiment [40]. Both methods can be used equivalently to obtain the RTD. Experimentally, the pulse experiment is known as the slug dose method where a large amount of tracer is instantaneously added to the incoming water [41]. A graphical method is generally used by plotting dimensionless tracer concentration (with respect to inlet value) at the tank exit as a function of time and directly read the concentration that corresponds to $t_{10}$. The pulse experiment is considered in the sequel for further analysis of the flow of the disinfection tank. It consists of a step injection of a given amount of tracer at the inlet and the generation of the corresponding response curve at the outlet. The tracer concentration is therefore recorded at the reactor outlet as a function of time $t$. The $\mathbf{E}$ curve is simply obtained after normalization with respect to the total amount of tracer injected [40]. The numerical equivalent of the pulse experiment is considered in the sequel. The methodology is devised into the following steps:

1. For a given flow rate, perform a steady state calculation with only water at the inlet ( water mass fraction $=1$, tracer mass fraction $=0$ ).

2. Once a steady state solution is reached, a transient calculation of tracer transport is initiated. The tracer mass fraction is set to 1 and water mass fraction to 0 for the very first time step.

3. After the first time step, mass fraction of water is set back to one, the tracer mass fraction to 0 and the transient simulation is continued. An average value of the mass fraction over all surface elements representing the reactor outlet is calculated at each time step.

Values recorded at the outlet are plotted against flow time, which gives the $\mathbf{E}$ curve. 
Several calculated parameters are used to assess tank behavior. Firstly, for a given flow rate $Q$, the theoretical flow time $t_{h}$ is calculated using:

$$
t_{h}=\frac{V}{Q}
$$

where $V$ represents the tank volume.

Secondly, all times $t$ recorded during numerical experiments are transformed into a dimensionless form, viz.

$$
\theta=\frac{t}{t_{h}}
$$

where $\theta$ represents the dimensionless time. In the sequel $\theta_{i}$ will denote the dimensionless time needed for $i \%$ of the tracer to exit the disinfection tank.

Table 1. Mathematical parameters used to assess tank behavior.

\begin{tabular}{cc}
\hline Short-circuiting & $\theta_{0}$ \\
& $\theta_{10}$ \\
\hline Mixing, dispersion & $\theta_{75}-\theta_{25}$ \\
& $\theta_{90}-\theta_{10}$ \\
& $\theta_{90} / \theta_{10}$ \\
& Variance (Var) \\
\hline Efficiency & $\theta_{50}$ \\
\hline
\end{tabular}

The $\mathbf{E}$ curve is then used to deduce several mathematical parameters that reflect, short-circuiting, mixing, dispersion and efficiency [19, 39] (see Table 1). Short-circuiting is inversely proportional to the dimensionless values $\theta_{0}$ and $\theta_{10}$. Mixing and dispersion are directly associated to the width of the $\mathbf{E}$ curve and thus the differences $\theta_{75}-\theta_{25}, \theta_{90}-\theta_{10}$ as well as the ratio $\theta_{90} / \theta_{10}$, often called Morril (Mo) index, very sensitive to short-circuiting [14, 39]. It is clear that for an ideal plug flow, Morril index is equal to 1 [28], while both differences of dimensionless times are equal to zero. Note that the variance is also used to assess mixing (reflects the extent of the spread of the $\mathbf{E}$ curve) and $\theta_{50}$ often used as an efficiency indicator. 
The discrete form of the variance for a given numerical pulse experiment is expressed as:

$$
\operatorname{Var}=\frac{\sum_{i=1}^{n}\left(t_{i}-\bar{t}\right)^{2} w_{i} \Delta t_{i}}{\sum_{i=1}^{n} w_{i} \Delta t_{i}}
$$

where, $w_{i}$ represents the average tracer mass fraction at the tank outlet at time step $i, \Delta t_{i}$ the time step, $n$ is the total number of time steps after which no more tracer is recorded at the tank outlet and $\bar{t}$ the average time given by:

$$
\bar{t}=\frac{\sum_{i=1}^{n} t_{i} w_{i} \Delta t_{i}}{\sum_{i=1}^{n} w_{i} \Delta t_{i}}
$$

Assuming a constant time step throughout numerical pulse experiments and using $\sum_{i=1}^{n} w_{i}=1$ gives:

$$
\operatorname{Var}=\Delta t \sum_{i=1}^{n}\left(t_{i}-\bar{t}\right)^{2} w_{i}
$$

and the average time $\bar{t}$,

$$
\bar{t}=\Delta t \sum_{i=1}^{n} t_{i} w_{i}
$$

After injecting equation (21) into equation (20), the variance is expressed as:

$$
\operatorname{Var}=\Delta t \sum_{i=1}^{n}\left(t_{i}-\Delta t \sum_{i=1}^{n} t_{i} w_{i}\right)^{2} w_{i}
$$

\section{Simulation results and discussion}

Numerical simulations are carried out for each tank using various water inlet flow rates. Four flow rates of 1.5, 3.0, 6.0 and $12.0 \mathrm{~m}^{3} \cdot \mathrm{s}^{-1}$ are simulated respectively. These values are chosen based on the actual functioning of East Algiers disinfection tank, knowing that the latter has been designed to operate flow rates ranging between 3.0 and $6.0 \mathrm{~m}^{3} \cdot \mathrm{s}^{-1}$. The numerical experiment, as already described, consist of reaching first a steady state for a given flow rate. Then, a transient 
simulation is performed to reproduce the pulse experiment. The time step for all experiments is set to $5 \mathrm{sec}$.

\subsection{Rectangular Tank}

The rectangular tank steady state results for $3 \mathrm{~m}^{3} \cdot \mathrm{s}^{-1}$, are shown in Figure 7 . Streamlines are colored by velocity module.

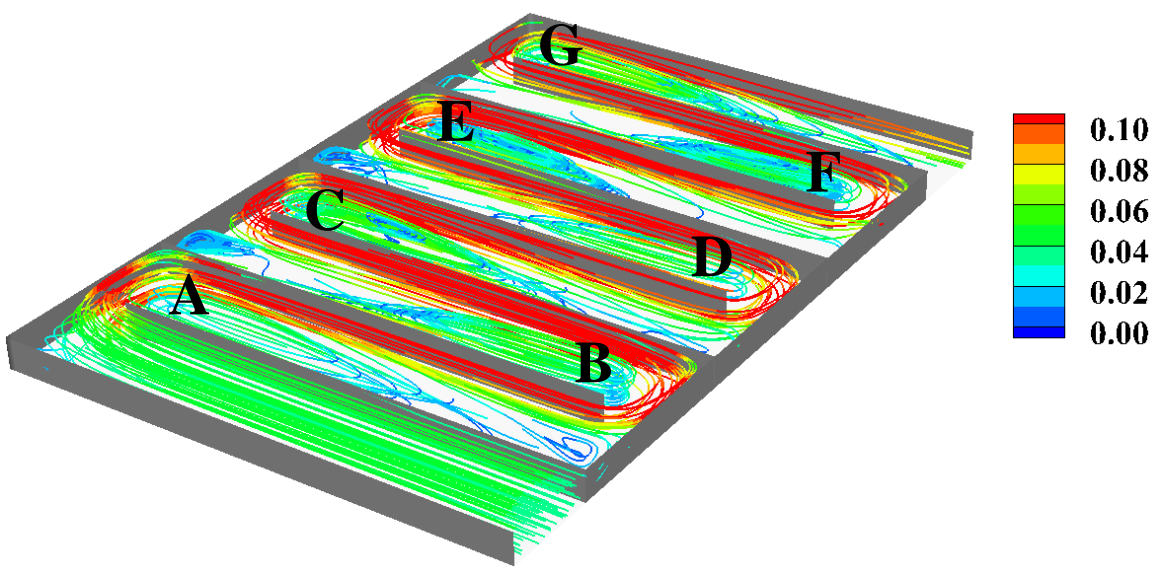

Figure 7. Rectangular design: streamlines for a flow rate of $3 \mathrm{~m}^{3} \cdot \mathrm{s}^{-1}$ (color by velocity module in $\left.\mathrm{m} \cdot \mathrm{s}^{-1}\right)$.

The fluid progresses smoothly through the first channel then accelerates as soon as it flows around the first baffle across a narrow gap with the creation of a large recirculation loop (zone A). Similar dead zones are created at the entrance of each channel defined by two successive baffles (zones B to G). Water flows faster near the baffles sidewalls with velocity exceeding $0.1 \mathrm{~m} \cdot \mathrm{s}^{-1}$.

Tracer responses for the numerical pulse experiments related to the four values of water flow rate are reported in figure 8. The $\mathbf{E}$ curve exhibits two different peaks. The first sharp peak, very pronounced for the highest flow rates is possibly due to short-circuiting (water fast flow along the red streamlines). The peak is immediately followed by a second peak related to the distribution of the remainder of the tracer. As the flow rate is decreased, the tail of the distribution spreads in time with small tracer mass fraction recorded after $60,000 \mathrm{sec}$ for a flow 
rate of $1.5 \mathrm{~m}^{3} \cdot \mathrm{s}^{-1}$. Both peaks seem to even out with decreasing flow rates and tend to merge since short-circuiting becomes less important.

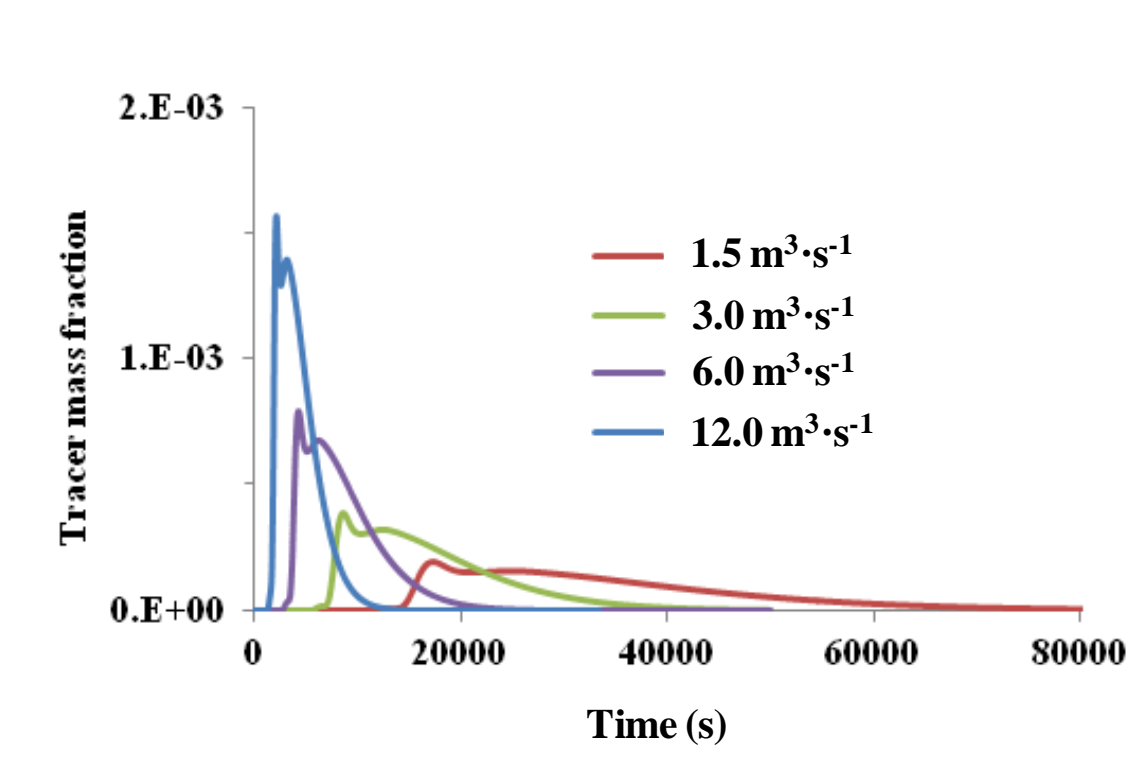

Figure 8. Rectangular design: tracer response for different flow rates.

Dimensionless flow times are grouped in Table 2 for all numerical experiments. No practical change is observed for $\theta_{10}$ and $\theta_{25}$, while a $10 \%$ and $21 \%$ increase is observed for $\theta_{75}$ and $\theta_{90}$ respectively, when flow is increased from $1.5 \mathrm{~m}^{3} \cdot \mathrm{s}^{-1}$ to $12 \mathrm{~m}^{3} \cdot \mathrm{s}^{-1}$, due to the shorter tails observed for faster flows.

Table 2. Rectangular tank performance for different flow rates.

\begin{tabular}{ccccc}
\hline Flow rate $\left(\mathrm{m}^{3} \cdot \mathrm{s}^{-1}\right)$ & 1.5 & 3.0 & 6.0 & 12.0 \\
\hline$\theta_{10}$ & 0.542 & 0.540 & 0.536 & 0.534 \\
$\theta_{25}$ & 0.684 & 0.682 & 0.671 & 0.666 \\
$\theta_{75}$ & 1.267 & 1.243 & 1.182 & 1.144 \\
$\theta_{90}$ & 1.642 & 1.579 & 1.441 & 1.354 \\
\hline
\end{tabular}




\subsection{Semicircular tank}

The semicircular tank has been designed to lessen the size of the external recirculation loops whenever water flows around the baffles. Figure 9 shows streamlines for a flow rate of $3 \mathrm{~m}^{3} \cdot \mathrm{s}^{-1}$. Even though the size of the dead zones has been reduced, they still prevail in each channel (zones A to G), creating fluid acceleration along the baffles sidewalls and possibly shortcircuiting.

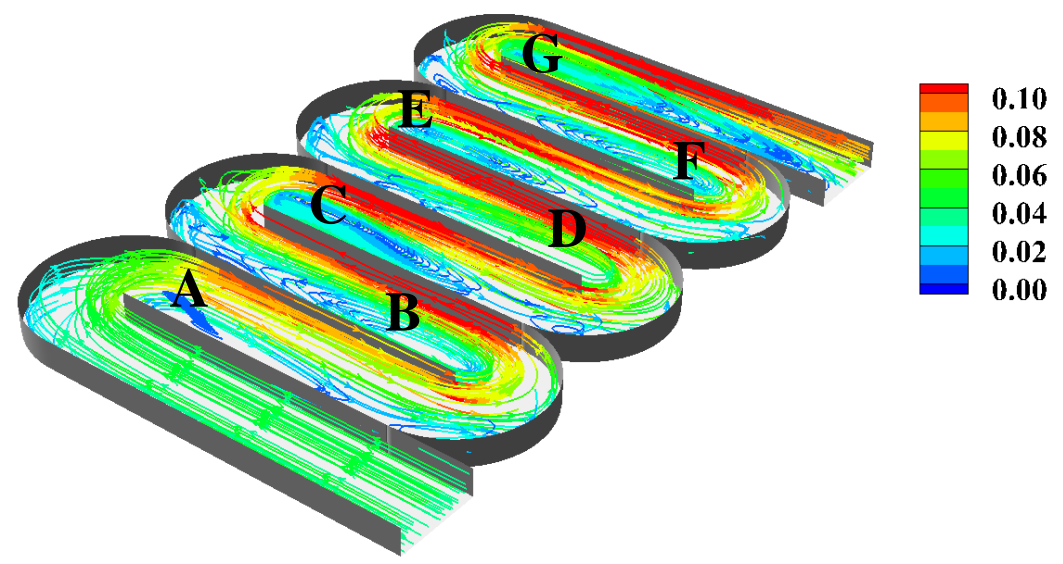

Figure 9. Semicircular design: streamlines for a flow rate of $3 \mathrm{~m}^{3} \cdot \mathrm{s}^{-1}$ (color by velocity module in $\left.\mathrm{m} \cdot \mathrm{s}^{-1}\right)$.

Tracer response as a function of flow rate is represented in figure 10. The curves show that shortcircuiting has been in fact reduced after the geometry has been smoothened out, since the two peaks observed in the rectangular geometry merged almost completely. 


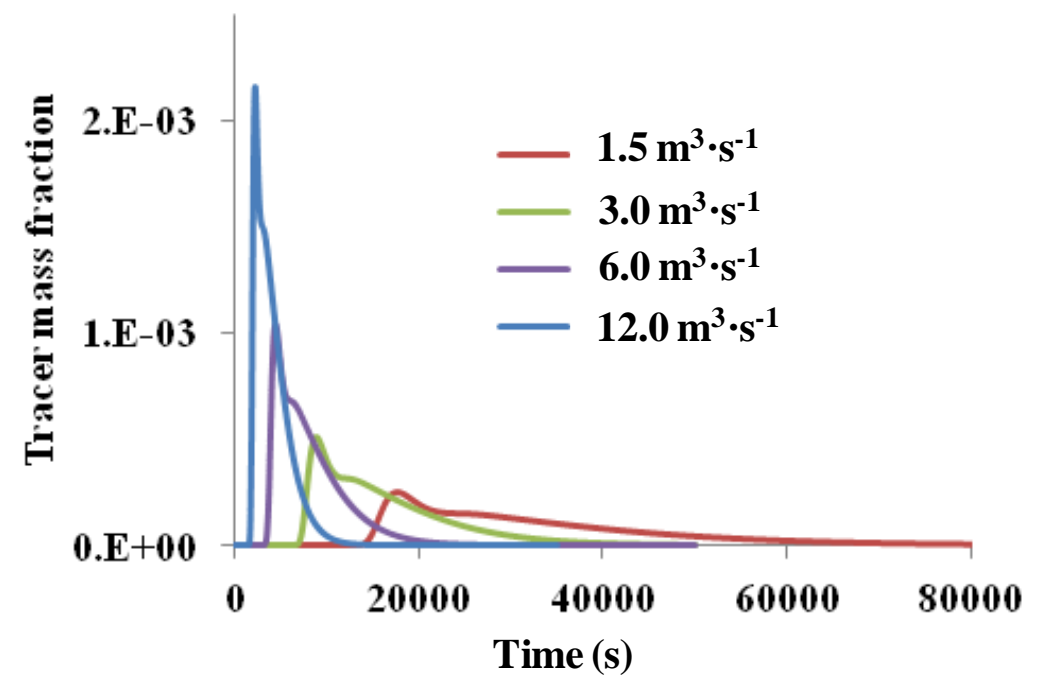

Figure 10. Semicircular design: tracer response for different flow rates.

Similarly to the rectangular designs, dimensionless times $\theta_{10}$ and $\theta_{25}$ remain unchanged, while $\theta_{75}$ and $\theta_{90}$ decrease by $19 \%$ and $39 \%$, respectively, when the flow rate increases from $1.5 \mathrm{~m}^{3} \cdot \mathrm{s}^{-1}$ to $12 \mathrm{~m}^{3} \cdot \mathrm{s}^{-1}$ due to less dispersion and a contraction of the $\mathbf{E}$ curve (see values in Table 3).

Table 3. Semicircular tank performance for different flow rates.

\begin{tabular}{ccccc}
\hline Flow rate $\left(\mathrm{m}^{3} \cdot \mathrm{s}^{-1}\right)$ & 1.5 & 3.0 & 6.0 & 12.0 \\
\hline$\theta_{10}$ & 0.529 & 0.528 & 0.527 & 0.524 \\
$\theta_{25}$ & 0.632 & 0.628 & 0.622 & 0.613 \\
$\theta_{75}$ & 1.243 & 1.199 & 1.124 & 1.044 \\
$\theta_{90}$ & 1.725 & 1.589 & 1.403 & 1.240 \\
\hline
\end{tabular}

\subsection{Circular Tank}

Streamlines colored following the velocity magnitude are depicted in Figure 11 for a flow rate of $3 \mathrm{~m}^{3} \cdot \mathrm{s}^{-1}$. Although the inlet surface is large, a recirculation loop is formed right at the tank 
entrance (zone A). Every time the fluid changes flow direction, relatively small dead zones are created (zones B, C, D, E and F). Moreover, at the reactor center, two large recirculation loops dominate the flow. At the vicinity of recirculation loops flow is faster (yellow to red streamlines), which could favor short-circuiting since water has a shorter residence time along the corresponding streamlines. Obviously, dead zones cause important deviations from plug flow.

Tracer response is recorded at the tank outlet for flow rates of $1.5 \mathrm{~m}^{3} \cdot \mathrm{s}^{-1}, 3.0 \mathrm{~m}^{3} \cdot \mathrm{s}^{-1}, 6.0 \mathrm{~m}^{3} \cdot \mathrm{s}^{-1}$ and $12.0 \mathrm{~m}^{3} \cdot \mathrm{s}^{-1}$, respectively (Figure 12). The shape of the curve suggests a combination of plug flow and mixed flow [40] especially for the highest flow rates. As the latter decreases, more dispersion is observed with the spreading of the $\mathbf{E}$ curve.

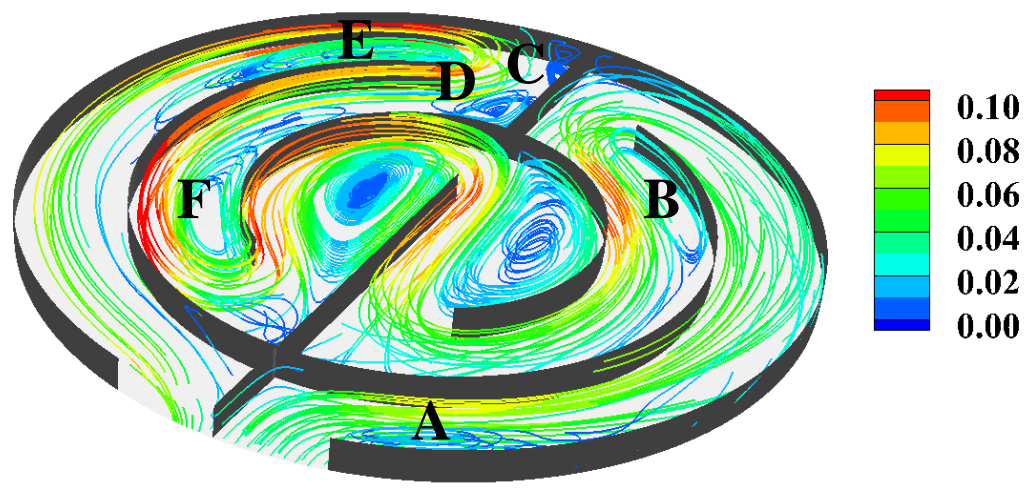

Figure 11. Circular design: streamlines for a flow rate of $3 \mathrm{~m}^{3} \cdot \mathrm{s}^{-1}$ (color by velocity module in $\mathrm{m} \cdot \mathrm{s}^{-1}$ ). 


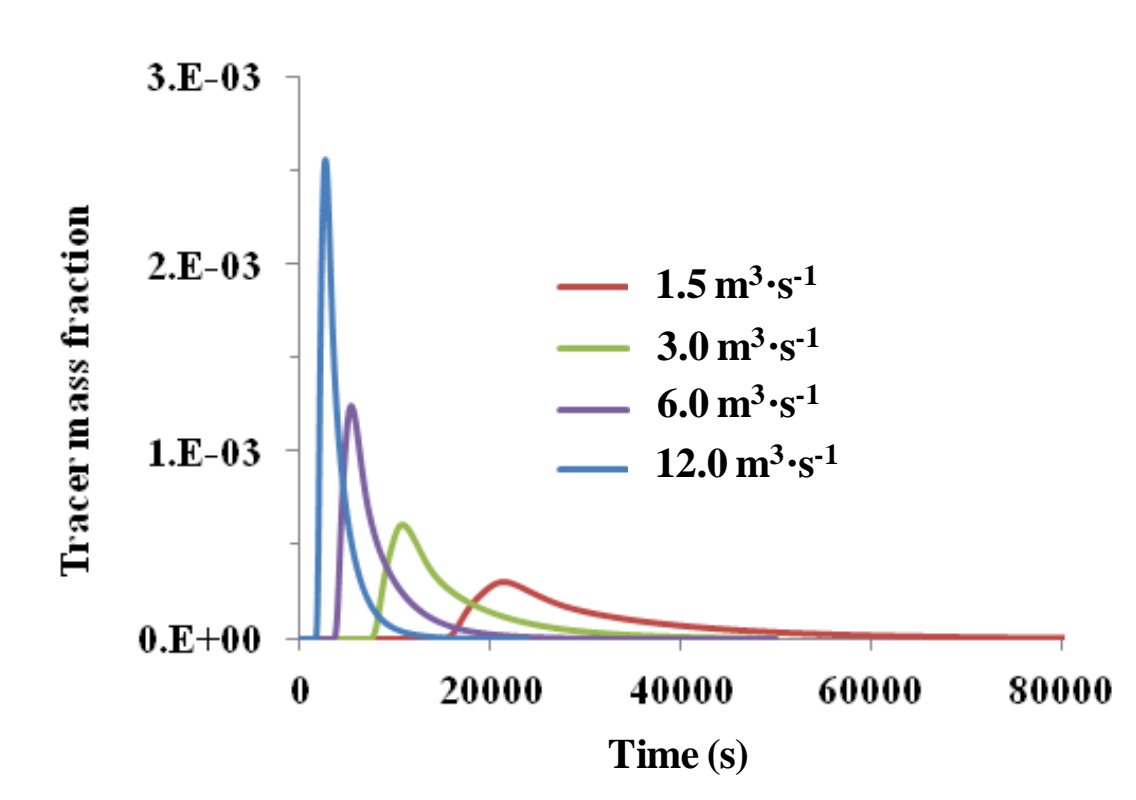

Figure 12. Circular design: tracer response for different flow rates.

Table 4 - Circular tank performance for different flow rates.

\begin{tabular}{ccccc}
\hline Flow rate $\left(\mathrm{m}^{3} \cdot \mathrm{s}^{-1}\right)$ & 1.5 & 3.0 & 6.0 & 12.0 \\
\hline$\theta_{10}$ & 0.578 & 0.583 & 0.578 & 0.568 \\
$\theta_{25}$ & 0.661 & 0.661 & 0.655 & 0.646 \\
$\theta_{75}$ & 1.112 & 1.079 & 1.025 & 0.958 \\
$\theta_{90}$ & 1.500 & 1.412 & 1.285 & 1.149 \\
\hline
\end{tabular}

Mathematical parameters deduced from the response curve of the circular design are summarized in Table 4 . The first three parameters $\theta_{10}, \theta_{25}$ and $\theta_{75}$ vary slightly compared to the $23 \%$ increase of $\theta_{90}$ when the flow rate decreases from $12 \mathrm{~m}^{3} \cdot \mathrm{s}^{-1}$ to $1.5 \mathrm{~m}^{3} \cdot \mathrm{s}^{-1}$ due to the stretching of the curve tail. 


\section{Archimedean spiral tank design}

The evolution from the rectangular design to the semi-circular then to the circular design showed that the smoothing of corners does bring improvement to the overall behavior of the tank. More specifically, it allowed the reduction of the recirculation loops and therefore brought the tank closer to plug flow. Ideally, a design would present no corners and no baffles. This is possible if the tank geometry follows the shape of an Archimedean spiral [42]. The main idea of this novel design is the total elimination of any sudden change in flow direction that may result in the development of flow dead zone.

The Archimedean spiral equation in polar coordinates is given by:

$$
r=a \alpha
$$

where $r$ is the radius, $\alpha$ the angle and $a$ is a constant defining the distance between the spiral arms. The arc length $S$, function of the angle $\alpha$, is expressed as [43]:

$$
S(\alpha)=\frac{1}{2} a\left\{\alpha \sqrt{1+\alpha^{2}}+\ln \left(\alpha+\sqrt{1+\alpha^{2}}\right)\right\}
$$

In order to set the size of the spiral, the gap $a$ and the angle $\alpha$ are needed. The distance between the spiral arms is set to $16 \mathrm{~m}$, which is the channel width used for the three tanks defined in figures 2, 4 and 5. Figure 13 shows the Archimedean spiral. After every $2 \pi$ rotation, the spiral radius has to increase by $16 \mathrm{~m}$. The constant $a$ can therefore be set to $16 / 2 \pi \approx 2.5$. In order to determine an appropriate spiral angle, the total spiral arc length is chosen equal to the total flow length of the rectangular design. The latter consists of eight adjacent channels of $88 \mathrm{~m}$ long, resulting in a total length of $704 \mathrm{~m}$ (Figure 2(a)). 


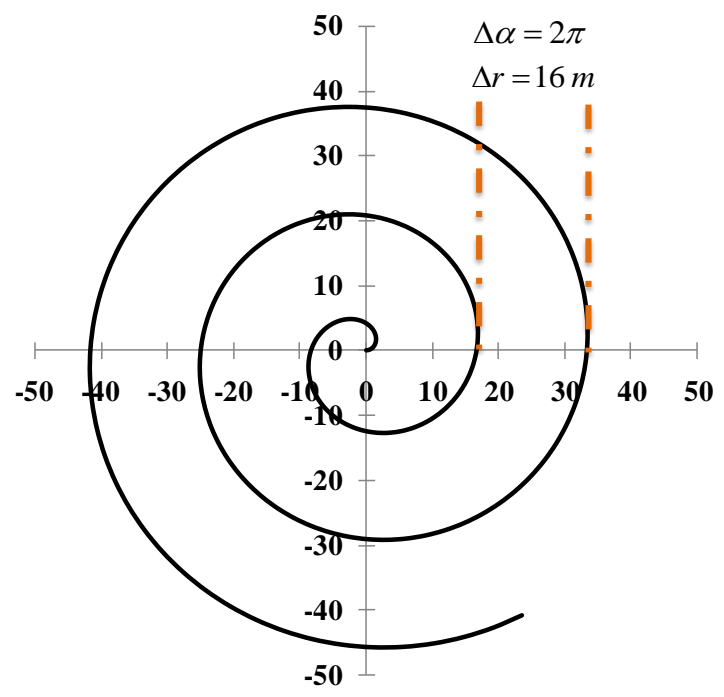

Figure 13. Archimedean spiral parameters determination.

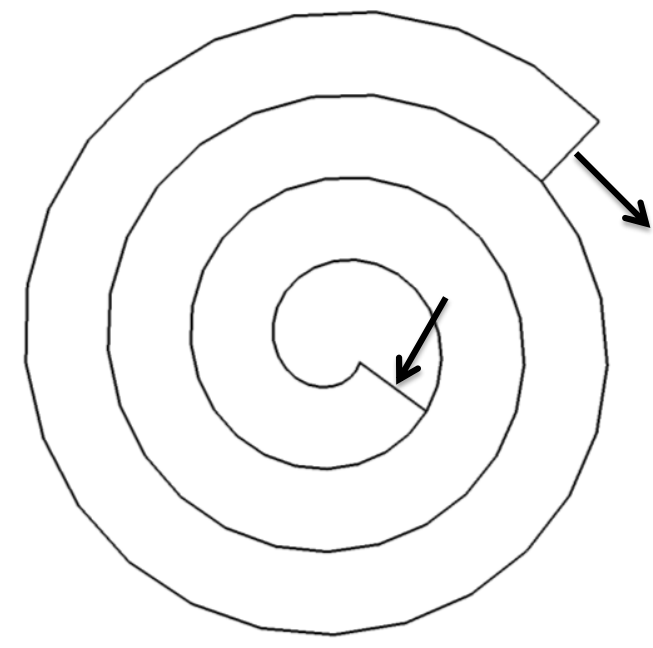

(a)

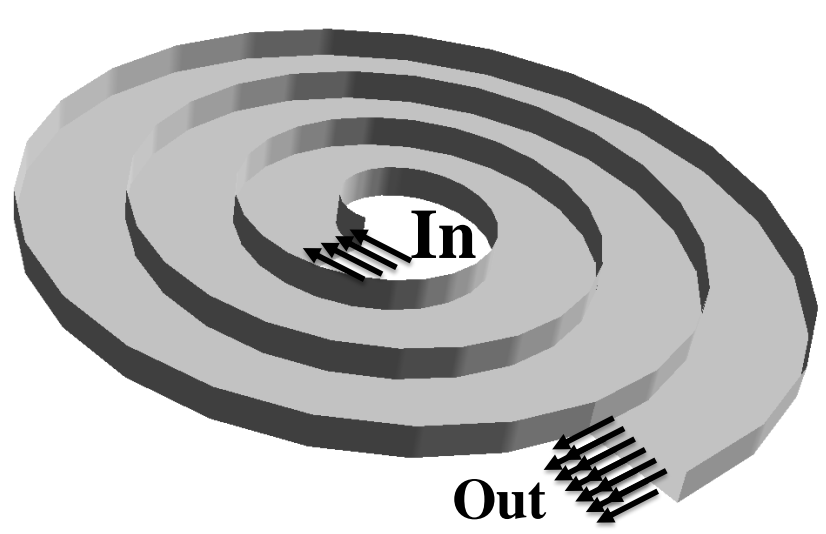

(b)

Figure 14. Archimedean spiral design: (a) top view, (b) three dimensional view.

Solving the non-linear equation (24) with $S(\alpha)=704$ gives an angle $\alpha=23.6$ radian, which is over two revolutions and a half. The center of the spiral is removed as shown in figures 14(a) and 14(b) in order to avoid the large curvature at the spiral departure. Using a $5 \mathrm{~m}$ height of water, the resulting volume is $49,800 \mathrm{~m}^{3}$. The geometrical model is meshed analogously to the classical designs with a vertical extrusion of the base pavement. The total number of hexahedral elements reached is 145,000 . 


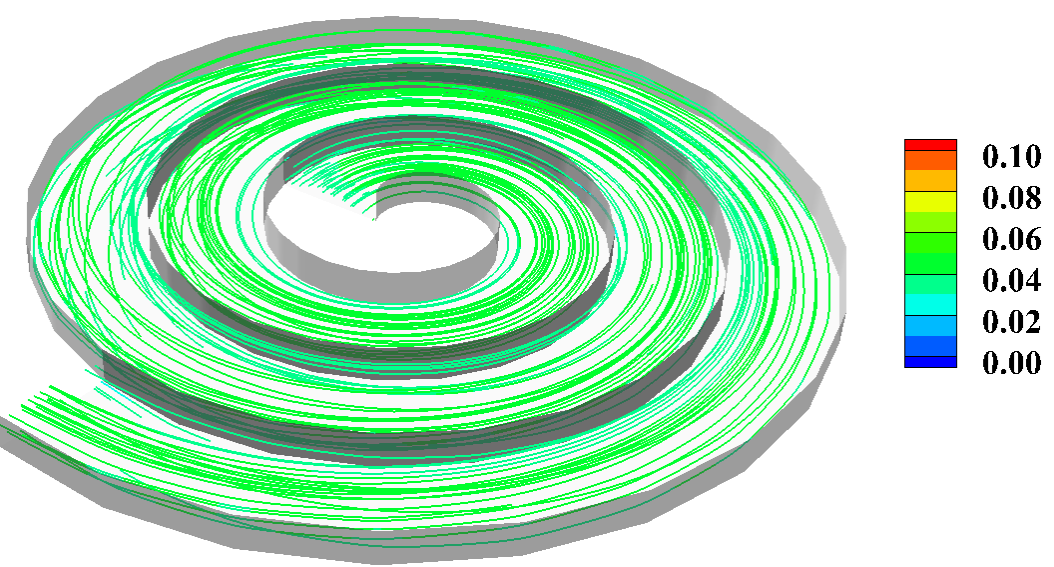

Figure 15. Spiral design: streamlines for a flow rate of $3 \mathrm{~m}^{3} \cdot \mathrm{s}^{-1}$ (color by velocity module in $\left.\mathrm{m} \cdot \mathrm{s}^{-1}\right)$.

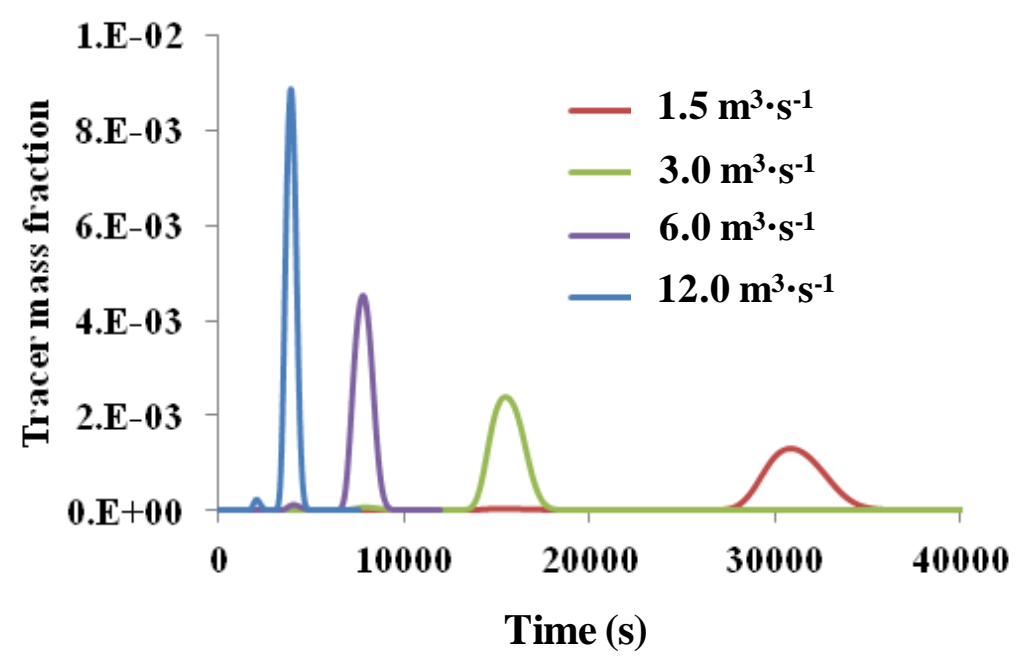

Figure 16. Spiral design: tracer response for different flow rates

Steady state simulations for the spiral design are performed for the four chosen values of water inlet flow rates. Figure 15 depicts streamlines for a flow rate of $3.0 \mathrm{~m}^{3} \cdot \mathrm{s}^{-1}$. Unlike the circular, rectangular and semi-circular designs, total nonexistence of recirculation loop is observed. Water smoothly follows the shape of the Archimedean spiral and keeps an average velocity value $\approx 0.5 \mathrm{~m} \cdot \mathrm{s}^{-1}$ along the tank channel. 
E curves for all numerical pulse experiments are presented in figure 16. For all flow rates, the tracer response is a symmetrical distribution with a single peak, suggesting no strong shortcircuiting. The distribution grows narrower with the flow rate to become much like a plug flow $\mathbf{E}$ curve. However, at larger flow rates, a very small peak is observed well before the main distribution, most probably due to a negligible short-circuiting caused by the slightly faster fluid evolving near the spiral outer sidewalls. More importantly, dimensionless times remain independent of the flow rate, and unexpectedly for the highest value of $12 \mathrm{~m}^{3} \cdot \mathrm{s}^{-1}$ (see Table 5).

Table 5. Spiral tank performance for different flow rates.

\begin{tabular}{ccccc}
\hline Flow rate $\left(\mathrm{m}^{3} \cdot \mathrm{s}^{-1}\right)$ & 1.5 & 3.0 & 6.0 & 12.0 \\
\hline$\theta_{10}$ & 0.875 & 0.869 & 0.859 & 0.849 \\
$\theta_{25}$ & 0.900 & 0.896 & 0.890 & 0.882 \\
$\theta_{75}$ & 0.960 & 0.961 & 0.959 & 0.904 \\
$\theta_{90}$ & 0.986 & 0.986 & 0.983 & 0.953 \\
\hline
\end{tabular}

\section{Tanks comparison}

In order to better assess the exceptional performance of the spiral design, $\mathbf{E}$ curves are represented on the same chart for a flow rate of $3 \mathrm{~m}^{3} \cdot \mathrm{s}^{-1}$ (see Figure 17). The three first designs respond similarly as early tracer mass fractions are recorder at similar times. It is clear that the spiral design behaves differently and species distribution appears much later with a symmetrical sharp peak while the distribution tail spreads in time for the other tanks. The CT concept is therefore more easily applied and is more reliable for the new design. Indeed, it is recalled that CT is the product of the residual chlorine $\mathrm{C}$ by the contact time $t_{10}$. The time $t_{10}$ depends strongly on the hydraulics of the tank and the recorded value will not reflect the behavior of the entire species population if it is not a plug flow, since species residence time could spread over a large period, thus experiencing higher chlorine reactivity. However, in the spiral design, the tracer remains grouped and resides evenly in the spiral design thus requiring less disinfectant. 


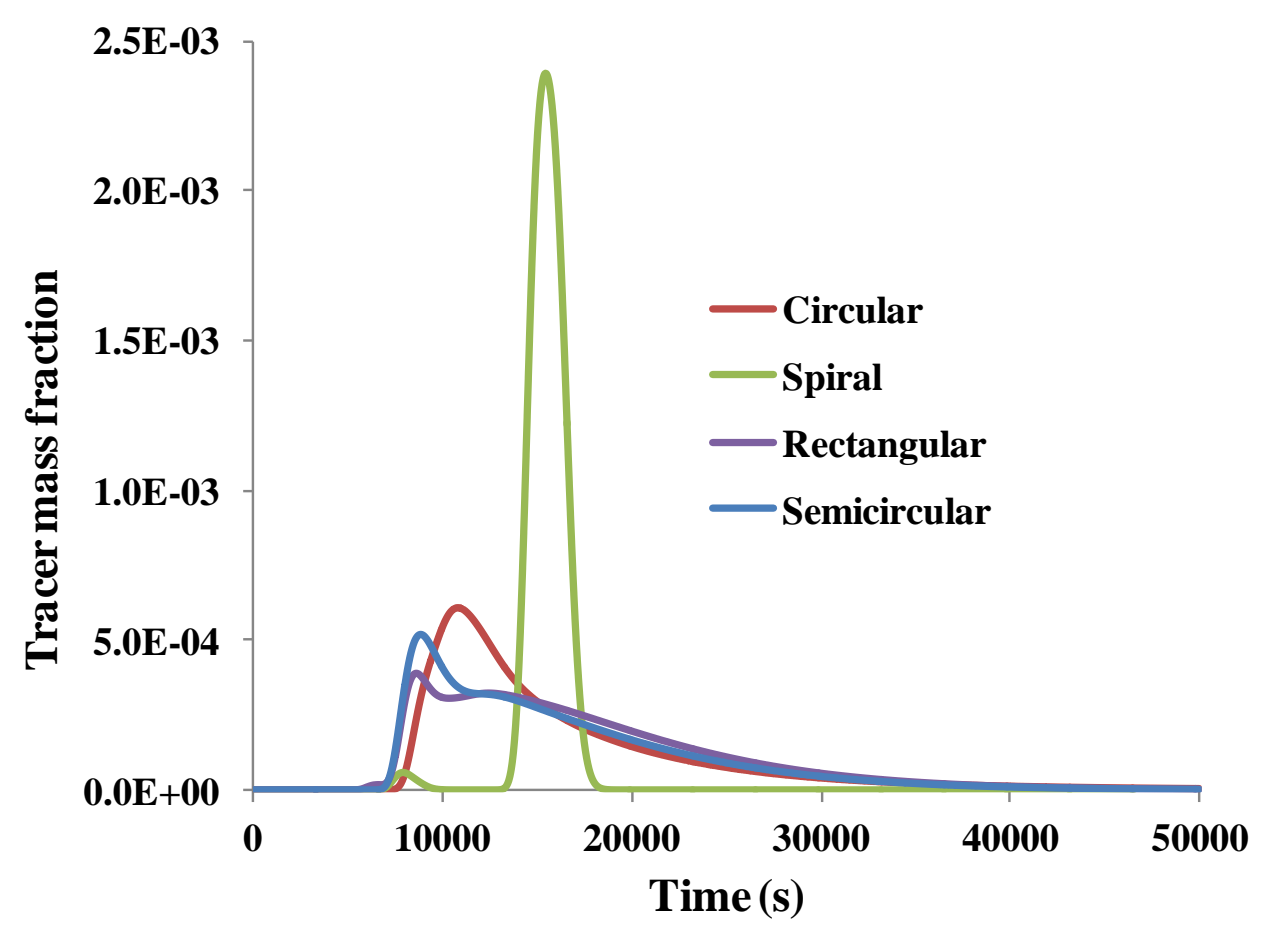

Figure 17. Tanks comparison: tracer response for a flow rate of $3 \mathrm{~m}^{3} \cdot \mathrm{s}^{-1}$.

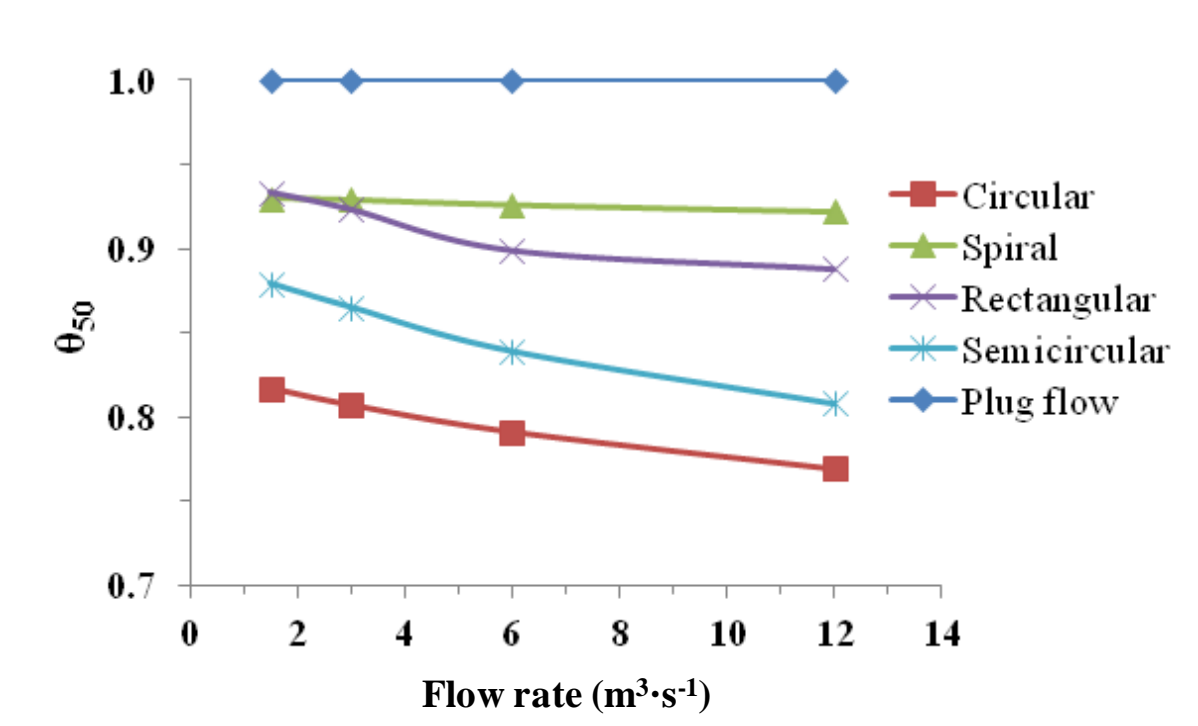

Figure 18. $\theta_{50}$ as a function of flow rate for different tank designs.

A more precise comparison of tank performance with respect to plug flow shows outstanding results. Figure 18 shows dimensionless time $\theta_{50}$ at which half of the total tracer mass exited the tank. The corresponding plug flow value is 1 . At the lowest simulated flow rate, spiral tank 
efficiency is similar to the rectangular one while the circular and the semi-circular tanks exhibit a much lower efficiency. However, as the flow rate increases, all tanks efficiency drastically drops except for the spiral design. The latter keeps a value of $\theta_{50}$ above 0.9 even for the highest flow rate of $12 \mathrm{~m}^{3} \cdot \mathrm{s}^{-1}$.

A measure of mixing and dispersion is the difference $\theta_{75}-\theta_{25}$, which is zero for the plug flow. Figure 19 shows that the spiral design is very close to plug $\left(\theta_{75}-\theta_{25}<0.1\right)$ flow while all other tanks have values all above 0.3 .

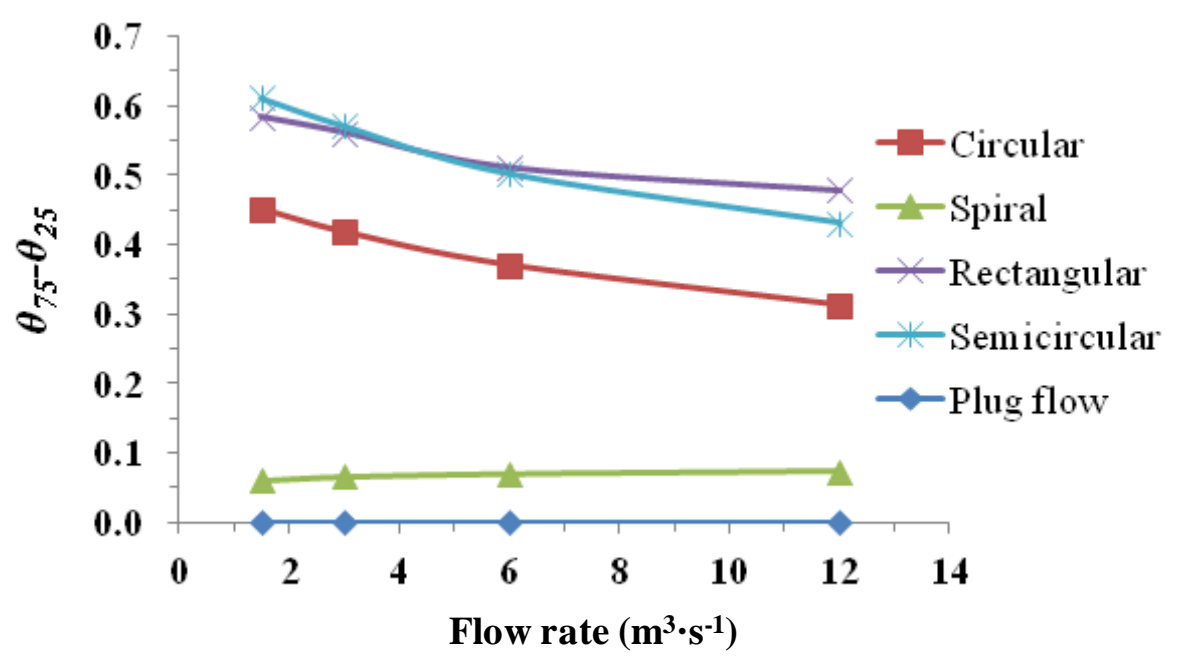

Figure 19. $\theta_{75}-\theta_{25}$ as a function of flow rate for different tank designs. 


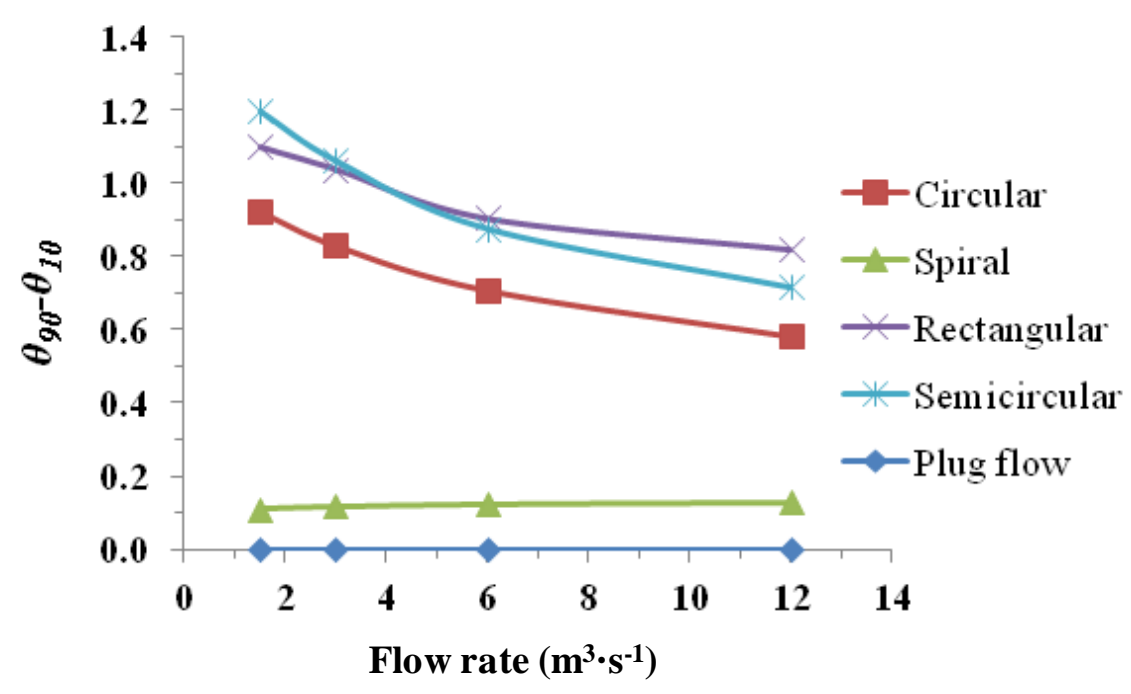

Figure 20. $\theta_{90}-\theta_{10}$ as a function of flow rate for different tank designs.

Interestingly, while all tanks show decreasing dimensionless time differences with increasing flow rate, the spiral tank exhibits a constant behavior almost independent from the flow rate. Analogously, $\theta_{90}-\theta_{10}$ for the spiral design is close to 0.1 throughout the whole range of investigated flow rates while the other designs show much higher values that tend to decrease with increasing flow rate (see figure 20).

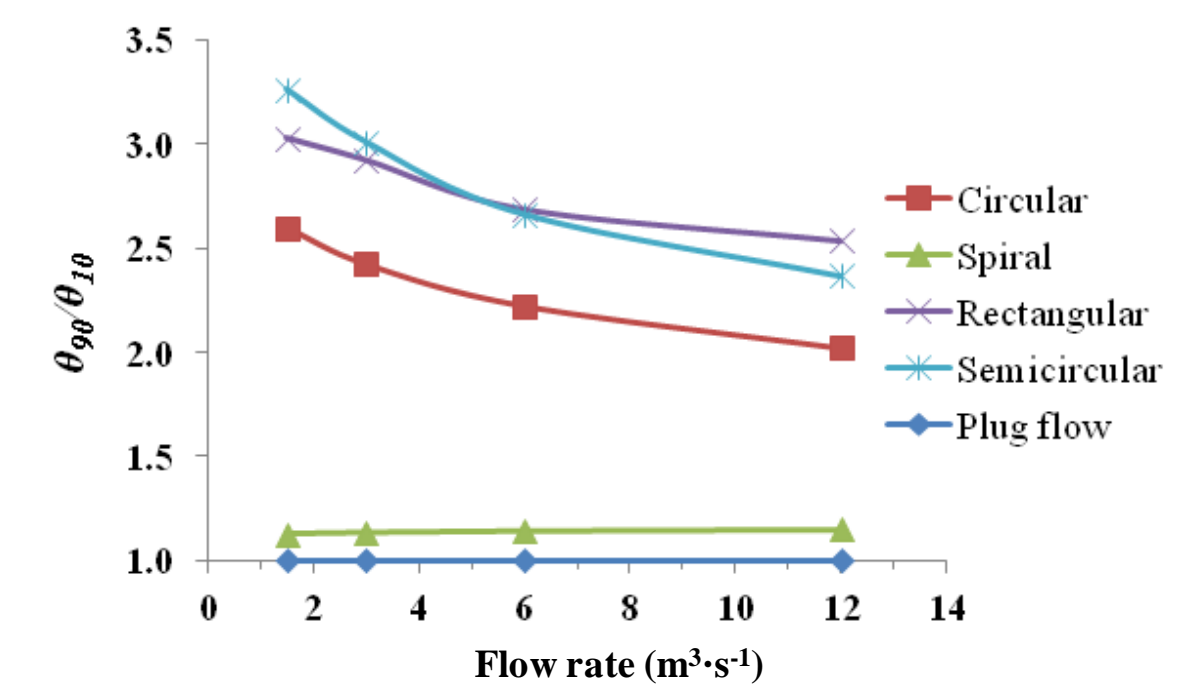

Figure 21. $\theta_{90} / \theta_{10}$ as a function of flow rate for different tank designs. 
Another measure of efficiency is Morril index $\theta_{90} / \theta_{10}$, equal to one for a plug flow. Figure 21 shows the ratio values for each type of tank as a function of the inlet flow rate. Again, the spiral design shows a nearly constant value, independent from the flow rate and close to plug flow. The other designs exhibit much higher ratios as seen on Figure 21.

The variance, a measure of the spread of the $\mathbf{E}$ curve, is directly linked to dispersion. The variance is equal to zero for plug flow since the latter has a response curve with no spreading. Figure 22 shows the variance for all tank designs. The spiral design gives results very close to plug flow and with nearly zero variance for slow flows, thus outperforming all other designs. Indeed all other tanks have variances one order of magnitude higher. However, all variances increase with flow rate, but remain small for the spiral tank with values well below 0.1 .

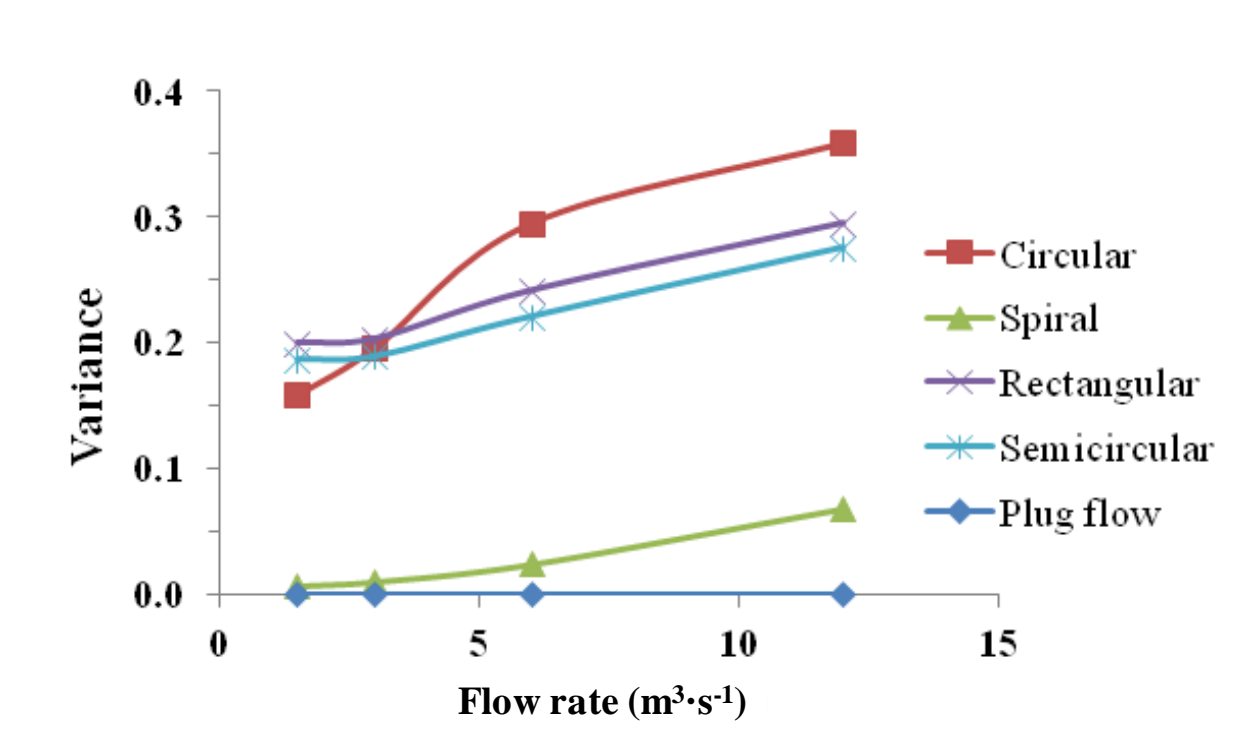

Figure 22. Variance $\sigma$ as a function of flow rate for different tank designs.

\section{Spiral tank size reduction}

Following the process intensification concept, size reduction of the tanks is desirable especially in areas where land is expensive. Tracer pulse analysis for all tanks at different flow rates showed that the spiral tank behavior is much closer to plug flow. Moreover, the tracer peak is shifted forward in time for this new design, allowing tracer species to stay grouped longer in the 
tank. Figure 16 showed that even for the highest flow rate used $\left(12 \mathrm{~m}^{3} \cdot \mathrm{s}^{-1}\right)$ the tracer peak appeared at around $60 \mathrm{~min}$, which is well above the $15 \mathrm{~min}$ minimum usually required for a proper disinfection [28]. The design seems to be well suited for size reduction. In order to assess the possibility to intensify the process, a drastic 50\% reduction of the tank size of both the rectangular and the spiral designs is carried out. Tracer pulse results are reported on figure 23 for a flow rate of $3 \mathrm{~m}^{3} \cdot \mathrm{s}^{-1}$. The $\mathbf{E}$ curve shows a peak centered at around $30 \mathrm{~min}$ for the spiral design, still complying to disinfection residence time constraint, while the flow through curve of the reduced rectangular tank appears too early (at around $13 \mathrm{~min}$ ) for a proper disinfection.

The same appraisal criteria are calculated for the reduced size, namely $\theta_{75}-\theta_{25}, \theta_{90}-\theta_{10}$, $\theta_{90} / \theta_{10}, \theta_{50}$ and the variance. All values for the reduced size are listed in Table 6 , together with values (between parenthesis) corresponding to the actual size.

Table 6. Design criteria for spiral and rectangular tanks after $50 \%$ size reduction (value between parenthesis represents criterion prior to size reduction).

\begin{tabular}{cccc}
\hline Criterion & Spiral design & Rectangular design & Plug flow \\
\hline$\theta_{75}-\theta_{25}$ & $0.086(0.065)$ & $0.461(0.561)$ & 0. \\
$\theta_{90}-\theta_{10}$ & $0.161(0.117)$ & $0.816(1.039)$ & 0. \\
$\theta_{90} / \theta_{10}$ & $1.19(1.135)$ & $2.42(2.924)$ & 1. \\
$\theta_{50}$ & $0.921(0.929)$ & $0.921(0.923)$ & 1. \\
Variance & $0.047(0.01)$ & $0.155(0.203)$ & 0. \\
\hline
\end{tabular}

It is clear that the new spiral design still outperforms the rectangular one; although a slight improvement is observed for the rectangular tank operation after size reduction, except that the tracer leaves the tank too early for proper disinfection (see Figure 23). Design criteria for the values in Table 6 show that the behavior of the Archimedean spiral tank remains close to plug flow values therefore retaining desired properties. Figure 24 compares the reduced spiral tank to the actual rectangular tank. Total tank surface is reduced by a factor of 4.7 after a $50 \%$ size reduction. Note also that the tank height is also reduced to $2.5 \mathrm{~m}$. 


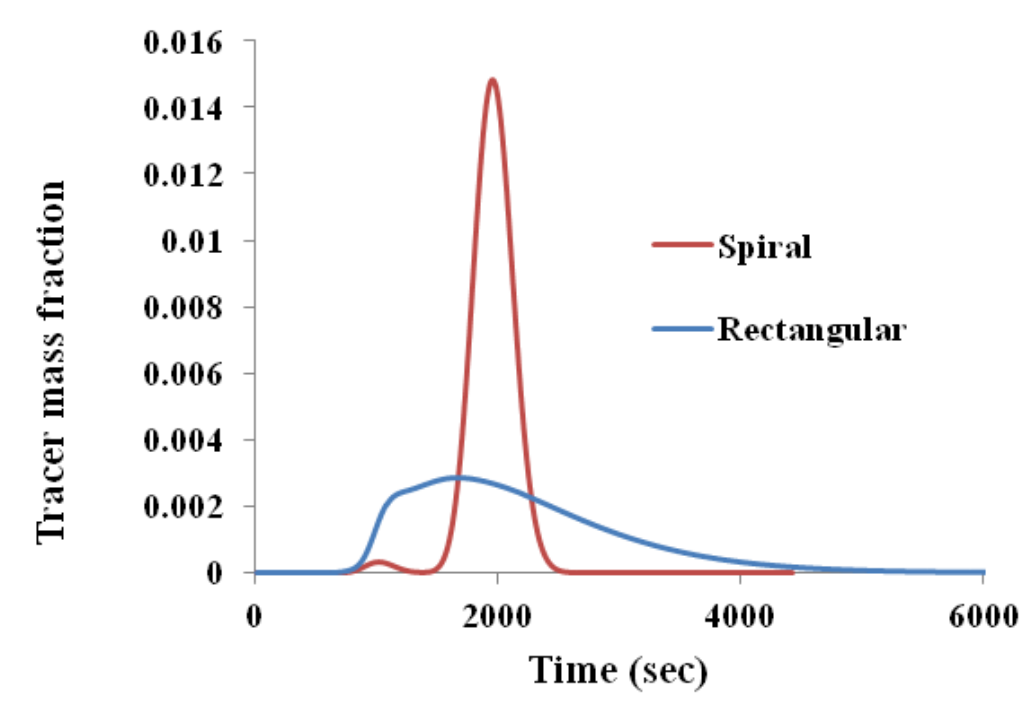

Figure 23. Tracer response after 50\% of size reduction of the spiral design for a flow rate of $3 \mathrm{~m}^{3} \cdot \mathrm{s}^{-1}$.
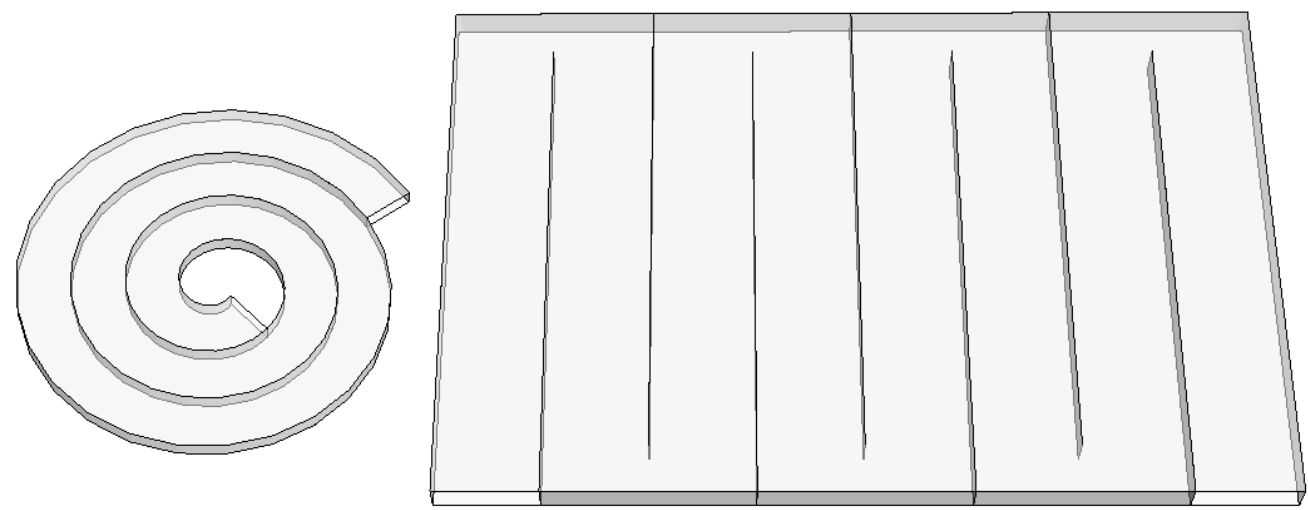

Figure 24. Size comparison: Archimedean spiral tank (reduced size) .vs. rectangular design (actual size).

Regarding its practical implementation, Figure 25 shows a possible use of the spiral design. A pipe brings water to the center of the spiral. The pipe can have supports on top of the spiral walls. The empty space around the center can be used as a quick mixing chamber then water flows over to discharge into the channel as depicted in Figure 25. 


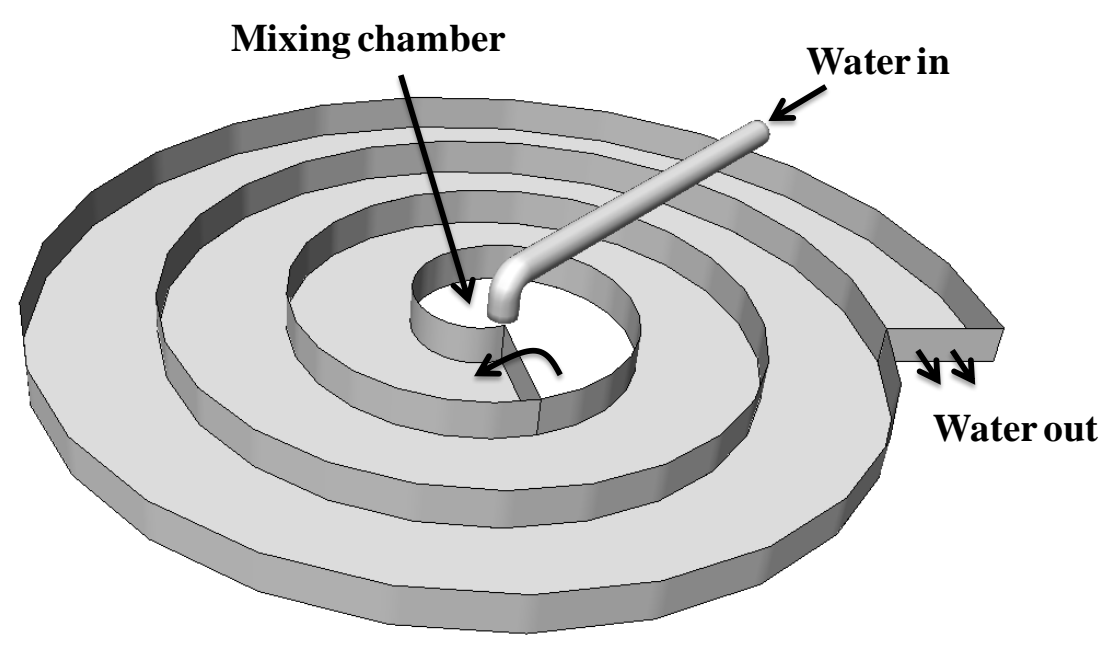

Figure 25. Spiral tank design operation.

Other feeding configurations are possible. Water can be fed from the bottom with a pipe placed under the tank. Similarly, Figure 26 shows how the direction of water flow could be changed, i.e. water in from the end of the spiral and water out from the center of the spiral.

Tracer response for both direct and reversed flow is shown in figure 27. Although spiral reversed flow seems to perform less better, the pulse keeps the same timing and both configurations strongly outperform the rectangular design.

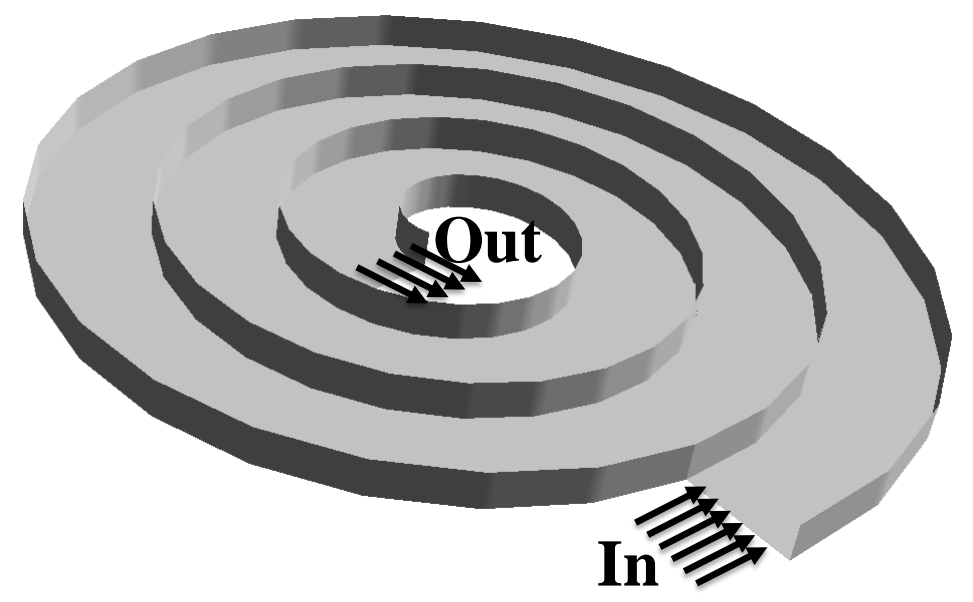

Figure 26. Spiral design reversed flow. 


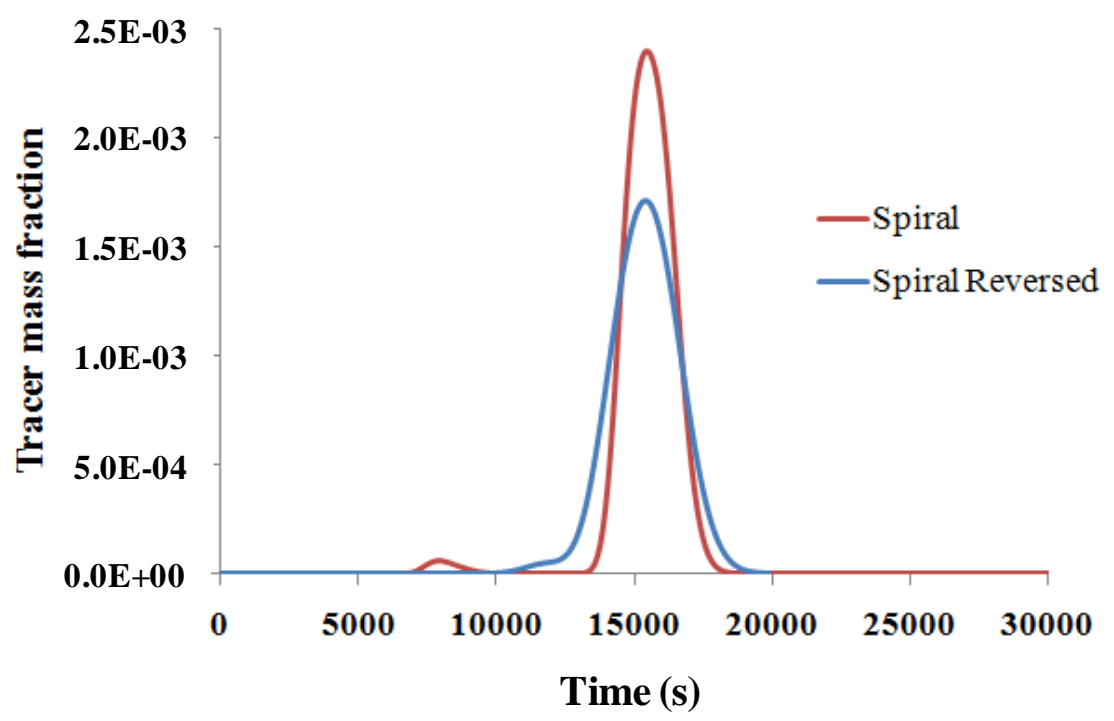

Figure 27. Spiral design: comparison of tracer response for opposite flow directions (flow rate $\left.3 \mathrm{~m}^{3} \cdot \mathrm{s}^{-1}\right)$.

\section{Conclusions}

A new spiral shaped reactor for water disinfection was presented. The design was compared to different tanks of similar volumes $\left(\approx 50,000 \mathrm{~m}^{3}\right)$ using a CFD tool namely ANSYS fluent [34]. Flow analysis showed that the unique shape enables the elimination of recirculation loops and dead zones enabling the fluid to evolve in parallel streamlines and relatively uniform velocity. It exhibits unprecedented performance assessed through a detailed RTD analysis. Numerical experiments of tracer pulses mimicking the experimental slug dose method allowed the generation of flow through curves and the calculation of several reactor design criteria that reflected the closeness of the Archimedean spiral to plug flow reactor. The new reactor offers a higher efficiency as it exhibits a relatively constant Morril index of 1.1 for all flow rates ( 1 for plug flow) while the index ranges between 2 and 3.3 for the other tanks. Less dispersion is also reported as $\theta_{75}-\theta_{25}$ is practically constant over the investigated range of flow rates and exhibits a value of 0.05 ( 0 for plug flow) while values between 0.3 and 0.6 are observed for the other designs. Similarly, the $\theta_{90}-\theta_{10}$ index has also been reduced from values as high as 1.2 for the semicircular design to 0.1 ( 0 for plug flow) for the spiral design. The results demonstrate that performance is not altered over the range of simulated flow rates, namely between $3 \mathrm{~m}^{3} \cdot \mathrm{s}^{-1}$ and 
$12 \mathrm{~m}^{3} \cdot \mathrm{s}^{-1}$. Furthermore, 50\% size reduction showed that the disinfection process could be strongly intensified with this new design while sustaining the same performance criteria. Finally, the tank implementation shows in principle no particular hurdle concerning its operation and maintenance.

\section{Nomenclature}

$a$ spiral constant

$k$ average turbulent kinetic energy $\left(\mathrm{m}^{2} \cdot \mathrm{s}^{-2}\right)$

$r$ spiral radius $(\mathrm{m})$

$t_{10}$ time needed for the $10 \%$ of tracer total mass to leave the tank

$t_{h}$ theoretical flow time (s)

$\bar{t}$ average time (s)

$u$ fluid velocity $(\mathrm{m} \cdot \mathrm{s})$

$w_{i}$ average tracer mass fraction at the tank outlet at time step $i$.

C disinfection concentration

$C_{1 \varepsilon} k-\varepsilon$ model constant

$C_{2 \varepsilon} k-\varepsilon$ model constant

CT product of disinfection concentration by contact time

E exit age distribution $\left(\mathrm{s}^{-1}\right)$

$G_{k}$ generation of turbulent kinetic energy due to mean velocity gradients $\left(\mathrm{kg} \cdot \mathrm{m}^{-1} \cdot \mathrm{s}^{-3}\right)$

Mo Morril index

Q flow rate $\left(\mathrm{m}^{3} \cdot \mathrm{s}^{-1}\right)$

$S$ spiral arclength (m)

T contact time 
$\mathrm{V}$ volume of the tank $\left(\mathrm{m}^{3}\right)$

Var variance

Greek letters

$\alpha$ spiral polar angle

$\delta$ Kronecker delta

$\varepsilon$ turbulent kinetic energy dissipation rate $\left(\mathrm{m}^{2} \cdot \mathrm{s}^{-3}\right)$

$\mu_{t}$ eddy viscosity $\left(\mathrm{kg} \cdot \mathrm{m}^{-1} \cdot \mathrm{s}^{-1}\right)$

$\mu$ dynamic viscosity $\left(\mathrm{kg} \cdot \mathrm{m}^{-1} \cdot \mathrm{s}^{-1}\right)$

$\theta$ dimensionless time

$\theta_{i}$ dimensionless time for $\mathrm{i} \%$ of the tracer to exit the disinfection tank

$\rho$ fluid density $\left(\mathrm{kg} \cdot \mathrm{m}^{-3}\right)$

$\sigma_{k}$ turbulent Prandtl number for the average turbulent kinetic energy

$\sigma_{\varepsilon}$ turbulent Prandtl number for the turbulent kinetic energy dissipation rate

$\Delta t_{i}$ time step (s)

\section{Acknowledgments}

The authors acknowledge software, computation and US patent application (provisional application No. 61/942,357 filed on Feb. 20, 2014) support from King Abdullah University of Science and Technology (KAUST), Saudi Arabia.

\section{References}

[1] G.A. Johnson, Hypochlorite treatment of public water supplies: Its adaptability and limitations, Journal of The American Public Health Association, (1911) 562-574. 
[2] F.F. Longley, C.A. Jennings, W.M. Jewell, M.B. Litch, W.M. Jewell, H.P. Letton, R.L. Sackett, J.A. Kienle, D.P. Curry, Present status of disinfection of water supplies, American Water Works Association Journal, 2 (1915) 679-692.

[3] E.M. Aieta, J.D. Berg, A review of chlorine dioxide in drinking water treatment, American Water Works Association Journal, 78 (1986) 62-72.

[4] K.P. Cantor, C.F. Lynch, M.E. Hildesheim, M. Dosemeci, J. Lubin, M. Alavanja, G. Craun, Drinking water source and chlorination byproducts: I Risk of bladder cancer., Epidemiology, 9 (1998) 21-28.

[5] G.A. Boorman, V. Dellarco, J.K. Dunnick, R.E. Chapin, S. Hunter, F. Hauchman, H. Gardner, M. Cox, R.C. Sills, Drinking water disinfection byproducts: Review and approach to toxicity evaluation, Environmental Health Perspectives, 107 (1999) 207-217.

[6] R. Sadiq, M.J. Rodriguez, Disinfection by-products (DBPs) in drinking water and predictive models for their occurrence: A review, Science of The Total Environment, 321 (2004) 21-46.

[7] S.D. Richardson, M.J. Plewa, E.D. Wagner, R. Schoeny, D.M. DeMarini, Occurence, genotoxicity, and carcinogenicity of regulated and emerging disinfection by-products in drinking water: A review and roadmap for research, Mutation Research, 636 (2007).

[8] C. Mercier Shanks, J.B. Sérodes, M.J. Rodriguez, Spatio-temporal variability of nonregulated disinfection by-products within a drinking water distribution network, Water Research, 47 (2013) 3231-3243.

[9] H. Chick, An investigation of the laws of disinfection, Journal of Hygiene, 8 (1908) 92-158.

[10] C.N. Haas, S.B. Karra, Kinetics of microbial inactivation by chlorine: I Review of results in demand-free systems, Water Research, 18 (1984) 1443-1449.

[11] C.N. Haas, S.B. Karra, Kinetics of microbial inactivation by chlorine: II Kinetics in the presence of chlorine demand, Water Research, 18 (1984) 1451-1454.

[12] H.E. Watson, A note on the variation of the rate of disinfection with change in the concentration of the disinfectant, Journal of Hygiene, 8 (1908) 536-542.

[13] D.G. stevenson, The design of disinfection contact tanks, Water and Environment Journal, 9 (1995) 146-152.

[14] J.M. Wilson, S.K. Venayagamoorthy, Evaluation of hydraulic efficiency of disinfection systems based on residence time distribution curves, Environmental Science \& Technology, 44 (2010) 9377-9382.

[15] R.A. Falconer, S.Q. Liu, Mathematical model study of plug flow in a chlorine contact tank, Water and Environment Journal, 1 (1987) 279-290.

[16] H. Wang, A.R. Falconer, Simulating disinfection processes in chlorine contact tanks using various turbulence models and high-order accurate difference schemes, Water Research, 32 (1998) 1529-1543.

[17] D. Kim, T. Stoesser, J.H. Kim, Modeling aspects of flow and solute transport simulations in water disinfection tanks, Applied Mathematical Modelling, 37 (2013) 8039-8050.

[18] D. Kim, T. Stoesser, J.H. Kim, The effect of baffle spacing on hydrodynamics and solute transport in serpentine contact tanks, Journal of Hydraulic Research, 51 (2013) 558-568. 
[19] A.I. Stamou, Verification and application of a mathematical model for the assessment of the effect of guiding walls on the hydraulic efficiency of chlorination tanks, Journal of Hydroinformatics, 4 (2002) 245-254.

[20] R. Amini, R. Taghipour, H. Mirgolbabaei, Numerical assessment of hydrodynamic characteristics in chlorine contact tank, International Journal for Numerical Methods in Fluids, 67 (2011) 885-898.

[21] Z.H. Taylor, J.S. Carlston, S.K. venayagamoorthy, Hydraulic design of baffles in disinfection contact tanks, Journal of Hydraulic Research, 53 (2015) 400-407.

[22] A.I. Stamou, Improving the hydraulic efficiency of water process tanks using CFD models, Chemical Engineering and Processing, 47 (2008) 1179-1189.

[23] D.J. Greene, B. Farouk, C.N. Haas, CFD design approach for chlorine disinfection processes, Journal (American Water Works Association), 96 (2004) 138-150.

[24] A. Angeloudis, T. Stoesser, R.A. Falconer, Predicting the disinfection efficiency range in chlorine contact tanks through a CFD-based approach, Water Research, 60 (2014) 118-129.

[25] J. Zhang, A.E. Tejada-Martínez, Q. Zhang, Developments in computational fluid dynamicsbased modeling for disinfection technologies over the last two decades: A review, Environmental Modelling \& Software, 58 (2014) 71-85.

[26] D. Fidaros, C. Baxevanou, A. Zagoritis, P.E. Mpiska, N. Vlachos, Numerical simulation of flow and transport phenomena in an urban wastewater chlorination tank, 10th International Conference on Environmental Science and TechnologyKos Island, Greece, 2007, pp. pp. A371A378.

[27] B.a.V. Corporation, White's handbook of chlorination and alternative disinfectants, fifth ed., John Wiley and Sons, Hoboken, New Jersy, 2010.

[28] V. Kothandaraman, R.L. Evans, Design and performance of chlorine contact tanks, 1974, V. Kothandaraman, R.L. Evans,

[29] J. Moles, Eaux de distribution, désinfection, in: E. T.I. (Ed.) Techniques de l'ingénieur2007.

[30] S. Lee, E. Shin, S.H. Kim, H. Park, Dead zone analysis for estimating hydraulic efficiency in rectangular disinfection chlorine contactors Environmental Engineering Science, 28 (2011) 25-33.

[31] R.A. Falconer, A.I.B.M. Ismail, Numerical modeling of tracer transport in a contact tank, Environment International, 23 (1997) 763-773.

[32] R. Falconer, S. Liu, Modeling solute transport using QUICK scheme, Journal of Environmental Engineering, 114 (1988) 3-20.

[33] ANSYS, CFX-5, ANSYS, Inc.

[34] ANSYS, fluent 13, ANSYS, Inc.

[35] D. Peplinski, J. Ducoste, Modeling of disinfection contactor hydraulics under uncertainty, Journal of Environmental Engineering, 128 (2002) 1056-1067.

[36] W.B. Rauen, A. Angeloudis, R.A. Falconer, Appraisal of chlorine contact tank modelling practices, Water Research, 46 (2012) 5834-5847. 
[37] ANSYS fluent 12.0: Theory Guide, 2009.

[38] T. Stoesser, C. Braun, M. Garcia-Villalba, W. Rodi, Turbulence structures in flow over twodimensional dunes, J. Hydraulic Eng., 134 (2008) 42-55.

[39] A.I. Stamou, G. Noutsopoulos, Evaluating the effect of inlet arrangement in settling tanks using the hydraulic efficiency diagram, Water SA, 20 (1994) 77-84.

[40] O. Levenspiel, Chemical reaction engineering, Third edition ed., John Wiley and Sons, New York, 1999.

[41] LT1ESWTR disinfection profiling and benchmarking: Technical guidance manual, EPA 816-R-03-004, 2003, U.S.E.P. Agency

[42] N. Ghaffour, Ait-Djoudi, F., W.M. Naceur, S. Soukane, Spiral-shaped disinfection reactors, United States Patent Application 20150232355

[43] E.W. Weisstein, Archimedes' spiral, MathWorld--A Wolfram Web Resource. 